Summer 8-22-2020

\title{
The Use of Tailored Interventions to Prevent Falls: A Quality Improvement Project in the Telemetry Unit
}

\author{
Roda Galang \\ University of St. Augustine for Health Sciences, r.galang@usa.edu \\ DOI: https://doi.org/10.46409/sr.YGXK7412
}

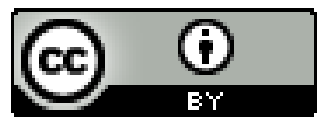

This work is licensed under a Creative Commons Attribution 4.0 License.

Follow this and additional works at: https://soar.usa.edu/scholprojects

Part of the Geriatric Nursing Commons, Occupational and Environmental Health Nursing Commons, Other Nursing Commons, and the Public Health and Community Nursing Commons

\section{Recommended Citation}

Galang, R. (2020). The Use of Tailored Interventions to Prevent Falls: A Quality Improvement Project in the Telemetry Unit. [Doctoral project, University of St Augustine for Health Sciences]. SOAR @ USA: Student Scholarly Projects Collection. https://doi.org/10.46409/sr.YGXK7412

This Scholarly Project is brought to you for free and open access by the Student Research at SOAR @ USA. It has been accepted for inclusion in Student Scholarly Projects by an authorized administrator of SOAR @ USA. For more information, please contact soar@usa.edu, erobinson@usa.edu. 
The Use of Tailored Interventions to Prevent Falls: A Quality

Improvement Project in the Telemetry Unit

Roda S. Galang MSN, RN

School of Nursing, University of St. Augustine for Health Sciences

This Manuscript partially fulfills the Requirements for the

Doctor of Nursing Practice Program

and is approved by:

Camille Payne, $\mathrm{PhD}, \mathrm{RN}$

Norma Teran, DNP, RN

August 2, 2020 


\section{University of St. Augustine for Health Sciences \\ DNP Scholarly Project Signature Form}

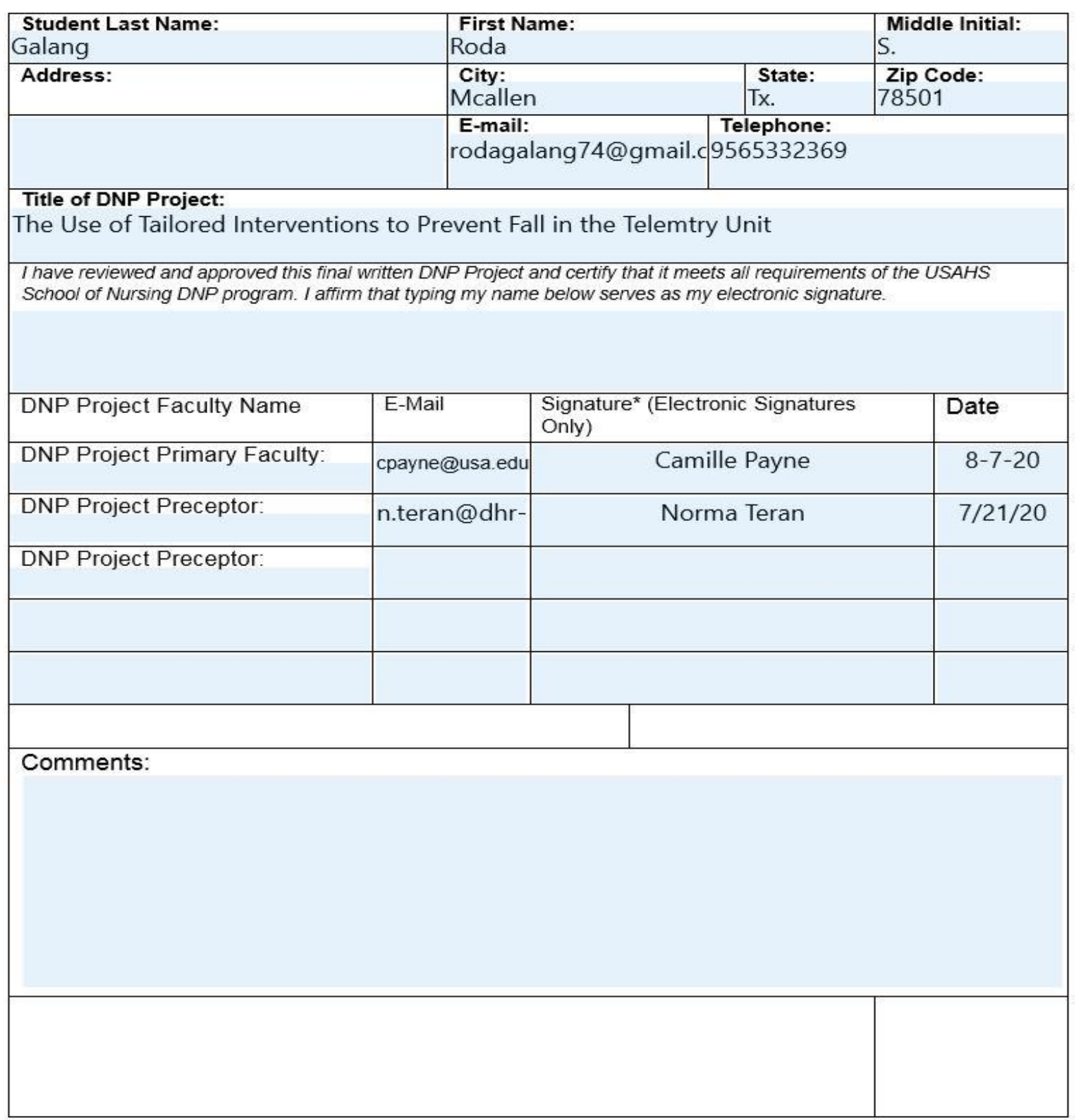




\begin{abstract}
Every year in the United States, hundreds of thousands of patients fall in hospitals with 30 to 50 percent resulting in injury. In Texas, the fall rate in adult patients is 33.9 percent, and in one teaching hospital in South Texas, patient fall rates have been above the national benchmark for two years (2017-2019), despite increased use of sitters for patient safety and multiple fall prevention strategies. The annual direct care cost of all fall events in the United States for individuals more than 65 years old is about $\$ 34$ billion. Objectives of the fall initiative program were increasing adherence to documentation of data from the Morse Fall Assessment and tailored interventions in the electronic health record. The goal of the project was to promote patient safety by decreasing the fall rate per 1000 patient days to below the national benchmark of 3.44/1000 patient days. The project was piloted in two telemetry units over 12 weeks using the Iowa Model of Evidence-based Practice. Telemetry staff received one-on-one education from the educator in the unit using a tailored intervention poster. The Nurse Champion observed 58 rooms and conducted chart documentation to ensure universal fall precautions were carried out during every shift. Incidence of falls was tracked daily, and post fall huddles were conducted after any incidents. The average monthly fall rate after implementation was $2.47 / 1000$ patient days, which was below the national benchmark. The fall assessment documentation in two telemetry units at DHR Health can be adapted or implemented hospital-wide. The results showed a statistically significant correlation between the Morse fall score assessment on EHR and monthly fall events $(p=0.0078)$. Champions were able to identify interventions and areas that needed to be improved such as education, patient engagement and stakeholder buy-in.

Keywords: Fall risk, fall checklist, fall prevention, Iowa Model of Evidence-based Practice Morse Fall Assessment, fall-tailored intervention
\end{abstract}


The Use of Tailored Intervention to Prevent Falls: A Quality Improvement Project

In the hospital and community settings, predicting which patient is most likely to fall is a continuous challenge because of the aging process, physiological conditions, medication and procedures that can leave them weak and confused (Joint Commission, 2015; Laycock, Bailie, Matthews, \& Bailie, 2019). In the United States, an estimated 1,000,000 patients fall in hospitals every year, and 30 to 50 percent result in injury (Health Research and Educational Trust, 2016; Wong et al., 2011). The Joint Commission (2015) considered falls as a top 10 Sentinel Event Alert, which is defined as "unexpected occurrence that involve death and serious physical and psychological injury" (2015, p.1). According to Galbraith, Butler, Memon, and Harty (2011), the average cost for a fall with injury is about $\$ 14,000$. In addition, patients with related injuries require additional treatment and increased hospital stays. Wong et al. (2011) noted a fall with injury added an average of 6 days to the hospital stay. Despite the ongoing innovations and improvements in healthcare and patient safety, falls are still one of the most preventable injuries in the US ("Preventing falls," 2015).

There is considerable evidence for effective fall prevention, and healthcare stakeholders are implementing quality improvement projects and evidence-based practices to protect patients from harm (Ayton et al., 2017; Dykes et al., 2017; Laulirn \& Shorr, 2019). There is a wealth of literature on fall prevention, and systematic reviews have identified effective interventions. However, there is limited research regarding healthcare providers' perspectives and roles in fall prevention (Cuesta Benjumea et al., 2017). Recommended successful strategies include the use of a standardized fall assessment, fall checklist, rounding tool, and tailored interventions (Dykes et al., 2017; The Joint Commission, 2015; Spano et al., 2018; Titler et al., 2015). The focus of 
this project was to implement an effective and proven fall prevention intervention that could become a best practice.

Moreover, the aims of the fall initiative project were to evaluate and measure the incidence of fall, fall rates, fall rates with injury, nurses' adherence to the quality improvement project and patient family engagement of the protocol. The desired outcome was to decrease falls below the national benchmark of 3.44/ 1000 patient days (AHRQ, 2013). In addition, a goal was established for a 75\% adherence rate for documentation of the Morse Fall Assessment and tailored intervention in the electronic health record and poster. This paper includes an evaluation of the outcomes of fall assessment with tailored intervention in the telemetry unit.

\section{Significance of the Practice Problem}

The hospital project setting fall rates have been above the national benchmark for almost two years in the National Database of Nursing Quality Indicators (NDNQI, 2019). Despite the increasing use of sitters for patient safety and multiple fall prevention strategies, the fall rates in hospitals continually increase. Sitters, who are certified nursing assistants, stay in the patient's room to observe and prevent falls. Fall rates above the national benchmark are public information and can cause a negative impact on the hospital's ratings and revenue (Boswell, Ramsey, Smith, \& Wagers, 2001). According to Spiva et al. (2012), hospitals spend over one million dollars on patient care sitters, and evidence shows that this trend will increase in the future. In addition, falls are the leading cause of fatal and non-fatal injuries among men and women aged 65 and older (Burns, Steven \& Lee, 2016). The medical cost of fatal falls is $\$ 637.2$ million and $\$ 31.3$ billion for non-fatal falls (Burns et al., 2016). According to the Centers for Disease Control and Prevention (CDC), the annual direct care cost of all fall events in the United States (US) for those who are more than 65 years old is about \$34 billion ("Cost of falls,” 2015). 
In addition, the effect of falls on patients and families is burdensome because of the delay in rehabilitation (Browne \& Sterne, 2019). According to the CDC (2018), approximately 33,000 fall-related deaths happened in 2015. Moreover, the average legal claim for a fall-related injury is about $\$ 55,000$ (Boswell et al., 2001). Focusing on effective and reasonable interventions can improve patient fall rates.

\section{Theoretical Framework}

The use of evidence-based practice (EBP) in healthcare organizations has improved patient outcomes by promoting safety and has helped many organizations in their reimbursements, which has controlled healthcare costs (Melnyk, Fineout - Overholt, GallagherFord, \& Kaplan, 2012). However, many hospitals are still using fall prevention programs despite the limited evidence from the literature to support their efficacy (Laws \& Crawford, 2013). This project utilized the Iowa Model of Evidence Based-Practice to promote patient safety and prevent harm. According to Brown (2014), the Iowa Model applied "triggers to help healthcare providers transform research results into clinical experience while enhancing quality outcomes for patients" (p.158). Triggers are internal or external data that identify a clinical problem. The Iowa Model's conceptual framework underlined pliancy in acknowledging the importance of high-level research, but recognized that this kind of evidence will not be always available (Buckwalter et al., 2017). In this evidence-based practice project, stakeholders needed to adapt to the best available data from the available practice recommendations (Buckwalter et al., 2017).

The Iowa Model conceptual framework steps were followed chronologically. The first step was the identification of the problem triggered by the data from risk management and the NDNQI. The fall rate for the past years has been above the national benchmark, and it was a clinical problem for the organization. The chief nursing officer and telemetry unit director 
recognized the problem triggers for change to facilitate patient safety. According to the Iowa Model, the data and the problem catalyze change (Brown, 2014). Assessing and aligning the priorities of the unit and organization improved opportunities for success (Titler et al., 2001). The second step was to form a team and assess current practice regarding falls and find evidencebased literature and clinical practice guidelines regarding falls (Titler et al., 2001). The literature review focused on increased fall rates above the national benchmark (Titler et al., 2001). The selected evidence-based literature and quality improvement project processes determined the accuracy of the practice recommendations proposed and the flexibility for modification, if necessary. In addition, selection of unit champions to help formulate, develop, implement, evaluate and sustain the quality improvement project was essential (Titler et al., 2001). According to Titler et al. (2001), an inter-professional team and buy-in from stakeholders were essential. The third step was piloting the change in practice (Titler et al., 2001). The Iowa Model helped structure the process of change and enabled rapid assessment of the fall poster checklist. The change was appropriate for adoption and stakeholders are looking to institute the change hospital-wide. Based on the literature review and synthesis (see Appendices B and C), the Iowa Model was an excellent model to translate evidence into practice.

\section{PICOT Question}

The PICOT question of the evidence-based practice project was: (P) Does use of fall assessment with tailored interventions for adult patients in the two-telemetry units (I) compared to selected universal fall precautions $(\mathrm{C})$ decrease the fall rate $(\mathrm{O})$ after three months of implementation $(\mathrm{T})$ ?

Fall was defined as "any descent to the floor with or without injury" (AHRQ, n.d.). The NDNQI definition for fall injury was: "None"- patient without injury; "Minor"- resulted in 
application of dressing, ice or limb elevation; "Moderate"- resulted in suturing or splinting; "Major" - resulted in injury like traction, fracture, or liver laceration and "Death"- patient died as result of injury caused by fall ("Preventing falls in the hospital," n.d.).

The Fall Assessment with Tailored Intervention Project was implemented for 12 weeks in the two telemetry units in one of the teaching hospitals at South Texas. The population was any adult patient admitted in the unit with a Morse Fall Score (MFS) of more than 0. According to AHRQ (2013), adapting the MFS tool in conjunction with clinical assessment to determine if a patient is at risk for fall was an effective intervention. The MFS scores are: MFS 0: No risk for falls, <25: Low risk, 25-45: Moderate risk and >45: High risk (AHRQ, 2013). All patients with MFS score of $>0$ had the specific tailored intervention.

The intervention combined an assessment and fall checklist with purposeful rounding. A list of the combination of interventions is presented on the Evidence Table to Reduce Falls (see Appendix C). There is strong evidence supporting the use of patient-centered checklists for effective fall intervention processes (Spano et al., 2018; Titler et al., 2015). According to Madeline and Morris (2019), the use of checklists as a hand-off and a rounding tool reduced patient falls because it determined whether all prevention interventions were carried out.

The telemetry units have implemented different quality projects to try to prevent falls. The unit did not have a specific protocol or policy regarding fall prevention. An updated, definitive policy was needed. The project was implemented for eight weeks. The baseline falls outcome performance (fall events with and without injury) for the two telemetry units was pulled from the hospital's internal database (see Appendix O). In addition, the following outcomes were measured monthly: fall rates, fall injury outcomes, and nurses' adherence to the protocol. The 
desired outcomes were a decrease in the fall rate to below the national benchmark $(3.44 / 1000$ patient days) and more than $75 \%$ adherence to the poster checklist prevention protocol.

\section{Literature Search Strategy}

The databases used to search the literature using PICOT question were PubMed, ProQuest and CINAHL. The search terms employed were: fall toolkit, fall checklist, fall prevention protocol, and fall checklist intervention. To help narrow the search, the following filters were used: English language, published within last five years, hospital setting, and patient participants. The initial search using the search terms and filters on three databases returned a total of 2,097 articles including duplicate articles. The inclusion criteria applied were systematic review, randomized controlled trials, qualitative study, quantitative study, mixed control study, patients, hospitals, adult, and healthcare hospitals. The exclusion criteria applied were: nonresearch, non-English language, non-intervention, commentaries, community dwellings, psychiatric, pediatrics, psychogeriatric, and hospice setting. Applying the inclusion and exclusion criteria resulted in 64 articles. Reading the full text and applying the inclusion and exclusion criteria resulted in 19 articles. However, 9 articles did not meet criteria. The 9 articles were removed and 1 article was added which met the criteria, and was recommended by the unit director. This resulted in a final 10 articles to synthesize (see Appendix A).

\section{Literature Results and Evaluation}

The DNP project leader appraised 10 articles using the John Hopkins Nursing Research Evidence Appraisal Tool (Dearholt, Dang, Deborah \& Sigma Theta Tau, 2012). Ryan, Mamaril and Swope (2017) recommended using the John Hopkins Tool to evaluate evidence when making recommendations to promote quality patient care. The DNP project leader graded the 10 articles using level of evidence and quality grade, which included five levels of evidence (Levels 
I-V) and quality grades (A-C). See Appendices B and C on the level of evidence and quality grades of each article.

All 10 studies answered the PICOT question. Most of the studies reported a decrease in fall rates with the use of a patient-centered fall assessment tool and checklist prevention program. There were only seven articles synthesized to develop evidence-based practice recommendations for building a fall prevention checklist intervention, other three articles were removed because the authors reviewed, assessed, and evaluated the efficacy of the EBP journals (see Appendices B \& C).

\section{Themes from the Literature}

The purpose of the systematic review was to examine evidence on the effectiveness of a checklist or toolkit in the management of falls. The review of the current evidence produced three themes that answered the PICOT question: Proper Assessment with Fall Risk Tools, Patient-centered Fall Checklist Intervention, and Consistent Preventive Fall Intervention for Sustainability. Adoption of these themes was the key to further reduce falls and the falls with injury in hospitals (Dykes et al., 2017). Moreover, providing staff with the evidence base behind fall preventions was an important part of the processes (Dykes, 2019).

\section{Proper Assessment with Fall Risk Tools}

The 2015 Sentinel Event Alert stated that inadequate assessment was the most common contributing risk factor for falls with injury (The Joint Commission, 2015). Duckworth et al. (2019) conducted a case control study to assess why patients who received the Fall TIPS Checklist Intervention fell. The results led to a conclusion that preventing falls in the hospital was a 3-step process. The fall risk assessment tool was a step in the intervention (Dykes et al., 2015). The American Geriatric Society's (2017) clinical practice guidelines summarized 
evidence-based recommendations to decrease fall and severity of injury by assessing the gait, balance and environment for safety. The Morse Fall Scale (MFS) is a tool used to identify risk factors for falls in hospitalized patients (Dykes et al., 2017). The total score may be used to predict future falls, but it is more important to identify risk factors using the scale and then plan care to address those risk factors.

The common components of fall risk assessment tools are history of fall, medication side effects, use of assistive devices (like a walker or cane), the use of IV poles or any equipment attached to the body, and unsteady gait. Dykes et al. (2017), Ambutas (2017), and Johnston and Magnan (2019) concluded the use of a fall risk assessment tool could help in tailoring patientcentered interventions. Moreover, using a fall risk assessment as the first step of intervention and arriving at a fall risk score by knowing the risk factors can mitigate the risk and help accurately implement fall interventions. Tzeng and YinYin (2015) conducted a non-experimental systematic review regarding patient-centeredness for fall prevention care and selected patientcentric and clinician-centric fall assessment tools that helped in fall prevention (see Appendices B and C). The authors concluded that these fall risk assessment tools could be key elements in fall prevention programs to close the gap in the intervention.

Melin (2018) piloted a 3-month pre- and post-intervention using the Morse Fall Risk Assessment with automatic intervention on EHR. A comparison of the pre- and post-intervention showed a decrease in the average monthly fall rate of 3.6 falls/1000 patient days. In addition, Dykes et al. (2017) and Titler et al. (2016) used the Morse Fall Assessment with checklist, and the results were significant reductions in fall rates (see Appendices B and C). Moreover, Titler et al. (2017) recommended assessing risk factors in order to make significant gains in decreasing falls. 


\section{Patient-Centered Fall Checklist}

A fall toolkit or checklist is a summary of essential components of treatment or interventions to promote adherence of the interventions. There were five articles that presented the use of checklist or toolkit in the fall prevention program (see Appendices B and C). A reasonable level of evidence exists that implementing toolkits (AHRQ, 2013) or checklists (Dykes et al., 2017) reduced fall rates (Ambutas, 2017; Ayton et al., 2017; Dykes et al., 2017; Johnston \& Magnon, 2019; Melin, 2019; Titler et al., 2016). See results in Appendix B.

Five of the studies were randomized control trials that tested the efficacy of fall toolkits. Ambutas (2017) used elements of the Agency of Healthcare Research and Quality (AHRQ) toolkit with minor revisions as a fall reduction program in two medical surgical units to assess effectiveness in reducing fall rates and falls with injury. Dykes et al. (2017) implemented the Tailored Intervention Program (TIPS) as a fall prevention tool to assess adherence of the protocol, reduction of fall rates, and fall rates with injury. Johnston and Magnon (2019) conducted a randomized controlled trial, and the project objectives were to assess compliance of nurses on the 14-step checklist fall intervention program. Ayton et al. (2017) used a 6 PACK fall prevention program to assess the effectiveness and usability of the toolkit. All of the studies had consistent results post- intervention: decreased fall rate and all other outcome measures (see results in Appendices B and C)

Moreover, Barker et al. (2017) assessed the 6 PACK checklist developed by Ayton et al. (2017), while Duckworth et al. (2019) reviewed the TIPS toolkit piloted by Dykes et al. (2015). In the reports of the 2 studies, the authors recommended the checklists as practical ways to prevent falls. 


\section{Consistent Prevention through Nursing Staff Adherence and Patient and Family Engagement}

The main influencing factors for adherence to the protocol were individual factors, including individual (clinical) experience, awareness, and the preference of following the plan of care. According to Ebben, Vlolet, Schalk, Mintjes-de Groot, and Van Achterberg (2014), the use of organizational factors to engage patients and nurses mitigated barriers for non-compliance. These factors were involvement in protocol, training, education, and being in accordance with daily practice (Ebben et al., 2014). According to Ambutas (2017), project goals were achieved through stakeholder support, promotion of staff accountability, and a continual evaluation process. Ayton et al. (2017) conducted a Level 1 randomized controlled trial (RCT) regarding the fall checklist intervention through nurse surveys. Two of the barriers identified were limited knowledge of fall prevention, and lack of ownership (Ayton et al., 2017). The Cuesta Benjumea et al. (2017) systematic review concluded that interprofessional collaboration in the intervention (including patient and family) was one of the best practices to prevent falls. Dykes et al. (2016) included educational material for families to promote engagement and to reduce falls (see Appendices B and C). Melin (2018) conducted a pilot study Level 1 RCT regarding fall prevention and reported that staff education and consistency in practice helped reduce fall rate (see Appendix B).

\section{Practice Recommendation}

The rigorous synthesis of the seven studies answered the PICOT question. The level of evidence based on the John Hopkins Appraisal Tool was Level III quality B because the metaanalysis and meta-synthesis had acceptable results regarding the use of fall risk assessment with checklist intervention in the reduction of falls. As seen in Appendix C, there was reasonable 
evidence that was consistent with the recommendation to use fall risk assessment, patientcentered intervention and consistent patient and nurse engagement to reduce falls (Ayton et al., 2017; Dykes et al., 2017; Johnston \& Magnon, 2019; Titler et al., 2017).

The practice recommendation that was used in the fall initiative program applied the three themes presented in the synthesis of the literature. The poster checklist consisted of the fall assessment with tailored intervention and patient and nurse engagement in consistent fall intervention. The poster checklist was a three-step process. The first step was to conduct a fall risk assessment using the Morse Fall Assessment. The second step was to develop a plan of care that was tailored to patient-specific areas of risk. The third step was to implement the plan consistently with nurse champions who engaged fellow nurses, patients and families in the intervention. According to Titler et al. (2015), clinician involvement in the fall risk assessment and use of fall prevention intervention targeted to patient specific fall risk decreased fall rates in 13 adult medical surgical units (see Appendix B). There was strong evidence to use the bundle or checklist for effective fall intervention processes if the intervention was specific to the patients' needs (Ambutas, 2017; Barker et al., 2017; Duckworth et al., 2019, Dykes et al., 2017). According to Dykes et al. (2019), staff needed to be involved in the process of tailoring and implementing the toolkit and of redesigning the workflow to engage patients and family in the 3step fall prevention process. The interventions were modified based on organizational policy and patient needs.

Moreover, Melin (2019) and Dykes et al. (2017) stated that fall prevention must be kept at the forefront of patient care, and that implementation of staff huddles and learning from feedback would sustain low rates of falls. 


\section{Project Setting and Overview}

The hospital project setting is one of the teaching hospitals in Edinburg. The hospital setting is a large, urban medical center located in southern Texas near the border of Mexico. The hospital project setting vision and mission are "To empower every caregiver to provide quality care with compassion and excellence to every patient in every encounter" (DHRHealth, n.d., para. 2). The hospital project setting purpose and vision are "To innovate, educate, and to provide continuous improvement in healthcare" (DHRHealth, n.d., para.2). The hospital project setting is a 520+ bed teaching hospital health system. The project was started in the two telemetry units, which had a total of 64 beds. The admitted patients were usually adults with multiple comorbidities, and most patients were greater than 18 years old. These patients required cardiac tele-monitoring, blood pressure medications, diuretics, and blood thinner medications, which could predispose them to increased risk for falls. The telemetry unit was a standard medical-surgical floor with cardiac monitoring. All rooms were exclusively private and there was a four-nurse station located in the middle of the unit.

The hospital project setting was currently integrating a sitter fall safety program. There was a need to increase education and compliance in its current policy in the telemetry unit, because the unit's quarterly fall rate for the last two years was more than the NDNQI benchmark of 3.44/1000 patient days ("Clinical and performance," 2019). In comparison, the organization telemetry unit's figure was 6.5/1000 patient days (DHR Health, 2019). The Chief Nursing Officer brought this problem to the attention of the director and clinical coordinator, and most stakeholders supported the efforts to reduce falls. During the meeting with the telemetry leaders, 
nurse champions in the unit were easily recognized. They were the educators, physical therapists, nurses' champions, and certified nursing assistants (CNA).

The vision and mission of the hospital project setting was achieved through the implementation of evidence-based quality improvement projects. The project objectives were to: 1) implement a fall assessment with a tailored intervention checklist to incorporate fall reduction strategies into practice; 2) improve staff knowledge of fall reduction measures, particularly those to reduce injury; 3 ) reduce falls with injury to less than 0.3 per 1,000 patient days; and 4) reduce falls without injury in the telemetry to less than 3.44 per 1,000 patient days. One of the shortterm objectives was to empower and educate nurses to apply the current evidence-based practice on fall prevention. The long-term objectives of this evidence-based practice project were to reduce fall rates and to achieve and sustain fall rates below the national benchmark.

\section{Project Plan}

The evidence-based practice project focused on establishing a consistent fall assessment with a tailored intervention prevention policy and establishing short-term objectives to achieve and sustain the project outcomes. The use of a poster checklist prevention reduced fall events, increased patient satisfaction, and improved the well-being of each patient. Consistent huddles for every fall event and engaging champions in the unit improved the teamwork and promoted patient safety. An organizational SWOT analysis revealed strengths, weaknesses, opportunities, and threats (see Appendix I). To sustain the project and close the gap with interventions, the strengths and weaknesses of the organization were evaluated. Organizational support and stakeholder support were essential for the successful implementation of the project. This evidence-based practice project was an opportunity for the project setting to improve fall rates, promote patient safety, increase revenue and improve patient outcomes. 
The framework model that was used in the quality project was the Institute for Healthcare Improvement Framework for Spread, or FFS (Nolan, Schall, Erb, \& Nolan, 2005). According to Nolan et al. (2005), the organizational stakeholders should be included when planning, developing and guiding the spread of new ideas. This model was appropriate to the organization because there was a lack of stakeholder engagement (see Appendix I). The FFS was helpful in guiding the project with the support and engagement of the leaders. The FFS has four phases: 1) prepare for spread; 2) establish an aim for spread; 3) develop an initial spread plan; and 4) execute and refine the spread plan (Nolan et al., 2005). See Figure 1 for illustration of FFS.

Prepare for Spread. Prior to project planning, the DNP project leader communicated the results of the SWOT analysis to the telemetry director, chief nursing officer, telemetry clinical educator, and clinical coordinator (see Appendix I). The unit director and most of their staff noticed the engagement on the existing fall prevention initiative. The unit director and clinical coordinator were very involved in the EBP change project. They provided critical help in identifying evidence-based literature to prevent falls. The telemetry educator and clinical coordinator were also on board and acted as champions of the fall initiative program. The Fall assessment with Tailored Intervention was an EBP practice in telemetry unit that can be adapted hospital wide for spread.

Establish an aim for the project. The fall rate was above the NDNQI national benchmark of 3.44/1000 patient days (AHRQ, 2015b). The desired outcome was a decrease of falls below national benchmark or a decrease of more than $50 \%$ in falls and fall injuries as well as more than $75 \%$ adherence to the fall initiative program.

Developing an initial spread plan. The DNP project leader communicated the EBP project during staff meetings. A gap analysis was conducted on current fall protocol and 
practices to evaluate barriers. These barriers were communicated to the unit director and clinical coordinator; as a result, protocols and the policy were revised.

Executing and refining the spread plan. Based upon the results of the fall prevention checklist gap analysis, the clinical coordinator revised the fall prevention policy. One-to-one education tools and poster training modules were used to train all staff on the two telemetry units. The education module focused on the following themes from the synthesis of the literature: electronic Morse Fall Scale assessment, patient-centered poster fall checklist intervention, and leaders' engagement in maintaining sustainability (see Appendices L and M).

The initial training was targeted for all nurses and champions in the two units, charge nurses, resource nurses, and nursing assistants. The clinical telemetry educator used the poster educational materials, conducted one-to-one training of all nurses, and secured a sign in sheet. Nurse Informatics presented the PowerPoint to the nurse champions and the Fall Assessment with Tailored Intervention was available on the electronic health record nursing care plan documentation (see Appendix M). The post-implementation project evaluation occurred in the first two weeks and every month. The time frame of the project was 12 weeks. There were monthly virtual meetings to assess adherence, and post huddles occurred consistently for every fall event to mitigate gaps right away. Data was collected monthly to evaluate fall rates, fall rate with injury, nurses' adherence to the protocol and patient engagement.

The initial estimated cost of the project was $\$ 13,397.70$. The calculation was based on department reviews and vendor recommendations, invoices and operational budgets to identify rates of pay for nurses and nursing assistants (see Appendix K). However, the expense budgeted was not approved due to a budget constraint. Instead, the telemetry educator provided one-to-one 
training during staff huddles. Therefore, the final cost of the project was only $\$ 6,677.00$ (see Appendix K).

\section{Project Evaluation}

The PICOT question of the evidence-based practice project was: (P) Does use of Fall Assessment with Tailored Interventions for adult patients in the two-telemetry units (I) compared to selected universal fall precautions $(\mathrm{C})$ decrease the fall rate $(\mathrm{O})$ after three months of implementation $(\mathrm{T})$ ?

The Morse Fall Assessment with Tailored Intervention Project occurred for 12 weeks in the two telemetry units. The DNP project leader evaluated the fall risk assessment and tailored intervention poster documentation for compliance. The DNP project leader audited all patients in the telemetry units ( $n=58$ ) using MFS. Each category of the assessment had individualized interventions that corresponded to the score. A score of 0 represented no risk for falls; <25: Low fall risk, and required individualized intervention; 25-45: had a moderate fall risk and required individualized intervention; and >45: had a high fall risk that required individualized intervention, as seen in Figure 3 (Dykes et al., 2017).

The bed poster was hung on the wall across from the bed and completed with the patient and family during admission and during every shift. The audit champions were the unit director, DNP project leader, clinical coordinator and Stryker bed liaison officer. The audit champions were trained to use the DHR Audit Tool Checklist. The telemetry director and clinical coordinator were very supportive throughout the project implementation and evaluation. Due to COVID-19, open communication occurred through email, text messages, calls, and virtual meetings. Updates of fall incidents were handled and reported every two weeks during quality and patient safety bi-monthly virtual meetings. 


\section{Data Collection}

The fall evidence-based practice program was implemented in the two telemetry units at DHR Health. The implementation of the Morse Falls Assessment with Tailored Intervention Education Checklist Poster (Appendix L) was a quality improvement change. All adult patients $(n=58)$ were evaluated for fall risk using the Morse Fall Assessment to assess any risk for falls. Based on their score, a specific tailored intervention was implemented.

The following interventions based on the MFS need to be documented on the EHR and communicated to the patient and family:

a) History of fall - educate and communicate circumstances of previous fall, fall signage and safety precautions;

b) Secondary diagnosis/ medication side effects - bedpan, assist to the commode or bathroom;

c) Ambulatory aid- consult physical therapy ambulatory aid at bedside;

d) IV therapy - assist to the bathroom, call light to ask for help;

e) Gait- assist out of bed and consult physical therapy;

f) Mental status- bed alarm, chair alarm, place patient on visible location, encourage family presence and frequent rounding.

In addition, the audit tool included hospital universal fall precaution interventions such as yellow socks, bed alarms, yellow gowns, call lights, fall signage, beds on the lowest position, two-side rails up and alarms. The DHR Fall Audit Tool (Appendix P) was used to collect data and evaluate compliance with the Morse Fall Assessment and documentation of the tailored intervention in the EHR. The tool was adapted from the Pennsylvania Patient Safety Fall Audit Tool (PSA, n.d.). In addition, the tool was reviewed and revised with further input and 
collaboration from the unit director, clinical coordinator and the Stryker Bed liaison officer. A pilot audit was conducted five days prior to the scheduled audit implementation to evaluate and clarify questions. The following pieces of information were missing and added to the audit tool: visual observation of the special equipment in use along with call light, two side rails up, checking Stryker Bed alarms to ensure they are on Zone 2, and green light is on if alarms are being used.

The first audit was performed on April 28, 2020 and every week for one month.

Moreover, during the audit, the DNP project leader used an online random number generator to determine which room would be audited, and a unique code that contained number and letters was used on each audit tool to protect patient privacy. All of the sample $(N=58)$ met the criteria, and MFS scores were all $>10$. The audit data were kept in the director's office. No patient information was collected on the audit tool. The audit tool used a unique code of letters and numbers next to the patient room number. The completed audit tools were collected at the end of the audit, and data were tabulated using Excel and Graph Pad Prism for appropriate statistical analysis and data visualization (Graph Pad, n.d.).

\section{Formative Evaluation}

Patients with a normal Morse Fall Score of "0" were excluded, and scores of 10 and higher were included in the fall evidence-based practice program. The process and outcome measures were evaluated for the fall process improvement and included: Increased patient and family engagement by identifying patient risk for falls; nurses' adherence to the tailored intervention, indicated by measuring the number or percentage of Morse Fall Assessment documentation on the HER; tailored intervention poster adherence; and nurse's documentation in the EHR. The DNP project leader used the DHR fall audit tool to measure nurses' compliance of 
the universal fall guidelines through environmental observation and documentation. The DNP project leader audited a total of 58 EHR charts and 58 rooms using the DHR fall audit tool. See Figure 1 for compiled data.

The DNP project leader collected and analyzed the data using percentages and counts to evaluate adherence of nurses on the tailored interventions documentation, assessment of the Morse Fall and observation compliance of the universal fall precaution. The data represented a total of 58 charts and 58 rooms on both the third floor and fourth floor telemetry units. Specific variables were tabulated on each floor to determine compliance and adherence of the quality project on each floor. Adherence and compliance data can be found in Appendices Q and R. In addition, data were aggregated on both floors to determine the significance of the interventions. This data is also in Appendices Q and R. The aggregated data show that $77 \%$ of the patients were Hispanic and 22\% were non-Hispanic. The nurses' adherence for completion of the Morse Fall Assessment was 94\%, which was documented on the EHR. Results from the study indicate that nurses were compliant on assessing patient Morse fall scores. In addition, $94.82 \%$ of these patients were identified to be at risk of falling. Tabulated data revealed that $87.93 \%$ of nurses did not adhere to the procedure of marking the poster intervention, and $67 \%$ did not document the Tailored Intervention in the EHR. Nurses' adherence to document on the poster as well as in the Cerner education documentation scored very low (see Appendices T and U). Based on these results, the DNP project leader and the Director planned to re-educate nurses and add online fall education. The DNP project leader and the DHR health educator are currently working an online mandatory class training for project sustainability. The education will include the Morse Fall Assessment with Tailored Interventions, and the EHR power form fall intervention documentation for sustainability of the project. 
The data displayed in Appendices Q and R showed visual observation audit assessment cues such as fall signage on the door (100\%) compliance, tailored intervention poster in the room (100\%), call light within reach (100\%), all rooms have a Stryker bed (98.27\%), and which rooms have the special alarm capabilities, resulting in high compliance. The result of nurses' adherence on two side rails up was $79 \%$, the bed on lowest position was $78.83 \%$, and wearing a yellow gown was $79.31 \%$. One interesting audit item was $75.86 \%$ patients wearing yellow socks, and red nonskid socks upon audit were counted as yellow socks, because red socks were not specified on the audit tool. Of the ten Stryker beds that have the alarm on, nine of the beds have the green light on, and seven are on zone 2 . The zone 2 and green light is a bed exit alarm for high-risk, confused patients who get out of the bed without assistance. According to Coussement et al. (2008), a bed alarm is the only intervention for patients who are confused and are at a very high risk of falling. Also, during the audit, there were 5 patients who used one-to-one sitters to prevent patient falls in addition to using the bed alarm.

Moreover, the tabulated results were presented to the telemetry director and the following measures were planned. The first measure planned was the sustainability measure, which included re-education regarding the adherence of the Fall assessment with tailored intervention to be done online and with an expected $75 \%$ adherence rate. Increasing the nurses' champions, and recruiting more nurses on each floor to continue the evidence-based practice project was discussed. The second measure planned was the financial measure. The total cost is presented in Appendix K, and additional costs will be added regarding increasing the size of the poster for good visualization, and ordering more yellow gowns and yellow socks. According to AHRQ, the cost of falls with associated injury is $\$ 7000$. There were no reported injuries on the post-fall huddle report. The third measure planned was the balancing measure; the number of sitters 
audited was five during the period of data collection, and each sitter cost $\$ 12.50 / \mathrm{hr}$, for a total cost of $\$ 750.00$. Moreover, there were no staff injuries reported on all the post huddle reports.

\section{Summative Evaluation}

The DHR Health Institute for Research and Development scientist and the DNP project leader used the Fisher's exact test and Chi-square for statistical analysis. The Fisher exact test and chi-square were used to check if there was a decrease or change in the fall event when these two variables were compared (intervention and outcome). The results of the data analysis of the following variables were analyzed: the Morse fall assessment and tailored intervention documented on EHR (Cerner) was not statistically significant with $p>0.999$, as seen in Appendix U ; the Morse fall assessment and tailored intervention documented on the poster did not make a difference with a $p>0.999$ (Appendix T); the Morse fall assessment and use of fall equipment were not statistically significant when data was run using a chi-square $p>0.9992$, as seen in Appendix V.

An additional analysis was conducted using a total of 54 eligible patient charts. The number of falls that happened in April and May (April was 60\% and May was 40\%) were analyzed to check if there was a decrease or change in the risk to fall. The MFS assessment documented on EHR was $16.67 \%$ in April and $83.33 \%$ in May. A Fisher exact two-sided test was used to determine the association between month vs. MFS assessment vs. fall events. The results showed a statistically significant correlation between the Morse fall score assessment on EHR and fall events $p=0.0078$, as shown in Appendix W. 


\section{Discussion}

The Fall Assessment with Tailored intervention is an adaptable evidence-based practice change. The process of the evidence-based practice project included a Morse Fall Score (MFS) and poster with tailored interventions. Nursing adherence to the MFS showed a statistically significantly higher compliance on the assessment and EHR documentation $(94.73 \%$, $p=0.0078)$. According to Dyke et al. (2010), the evidence-based fall prevention toolkit that included the Morse fall assessment showed $81 \%$ compliance on the control floor and $94 \%$ compliance on the intervention floor. The teaching hospital is accredited by the Joint Commission, and the fall prevention evidence-based practice project was a contract between the hospital and patients to promote patient safety. The telemetry average fall rate after implementation was 2.47/1000 patient days, which was still below the national benchmark of 3.44/1000 patient days (AHRQ, 2015b). The average monthly fall rate over the 12 -week implementation was 2.47/1000 patient days. Melin (2018) piloted a 3-month pre- and postintervention using the Morse Fall Risk Assessment with automatic intervention on EHR. A comparison of the pre- and post-intervention showed a decrease in the average monthly fall rate of 3.6 falls/1000 patient days (Melin, 2018). The fall assessment documentation in two telemetry units at DHR Health can be adapted or implemented hospital-wide. The results showed a statistically significant correlation between the Morse fall score assessment on EHR and monthly fall events $(p=0.0078)$.

Assessment is one of the key best practices recommended for fall prevention (Cuesta, Benjumea et al., 2017; Dykes et al., 2017; Melin, 2018; Titler et al., 2016). The tailored intervention and universal fall precaution guidelines based on the Morse Fall Score were part of the checklist. Adherence to documentation of the fall prevention on the poster was found to be 
low, as $87.93 \%$ of the posters were not marked, updated or completed. In addition, there was also low adherence to the recommendation to document the tailored intervention in the EHR $(36.07 \%)$. Therefore, the goal of $75 \%$ adherence on the education documentation was not met. Dykes et al., (2017), showed more than $80 \%$ adherence of the tailored intervention was achieved when patient and family were involved in the plan of care. During the project implementation and evaluation, family members and visitors were not allowed in the unit due to COVID-19, and this may have affected the results.

However, there was consistently high compliance with the universal fall precaution checklist. Components included fall signage on the door (100\%), tailored intervention poster in the room $(100 \%)$, call light within reach (100\%), and all rooms with a Stryker bed which had special alarm capabilities (98.27\%). Nurses' compliance adherence scores were: side rails up (79\%), bed in lowest position (78.83\%), patient wearing yellow gown $(79.31 \%)$ and patient wearing yellow socks (75.86 \%). According to Johnston and Magnon (2019), using a fall prevention checklist was a good safety check and identified frequently missed prevention interventions and areas for improvement in the hospital's fall prevention protocol. According to Coussement et al. (2008), a bed alarm is the only intervention for patients who are confused and are at a very high risk of falling. On Stryker beds with alarms, the Zone 2 and green light are bed exit alarms for high-risk, confused patients who get out of the bed without assistance. Also, the Zone 2 feature limits movement and sounds the alarm when the patient approaches the side rails or foot of the bed. The results of the bed audit indicated 10 of 58 $(17.24 \%)$ had the Zone 2 and green light turned on. Five patients used sitters to prevent patient falls in addition to using the bed alarm. Spiva et al. (2012) estimated the cost of sitters in acute care hospitals is about 1 million dollars a year. 
The last element of the evidence-based practice project was nursing staff engagement with patient and family. The evidence-based practice project showed high and acceptable nursing compliance and adherence to the fall assessment and universal fall precautions, including fall signage on the door $(100 \%)$, tailored intervention posters in the room (100\%), call light within reach $(100 \%)$, rooms with a Stryker bed $(98.27 \%)$, side rails up (79\%), bed in lowest position (78.83\%), patient wearing yellow gown $(79.31 \%)$ and patient wearing yellow socks $(75.86 \%)$. The staff engagement with patient and family showed a low compliance of $36.07 \%$ due to the COVID-19 pandemic. There were no family members available during admission or daily assessment to educate about the planned fall intervention. Inter-professional collaboration, patient and family education, and family engagement through providing educational materials are some of the best practices for fall prevention (Dykes et al., 2017; Cuesta Benjamea et al., 2017).

The Fall Assessment supports the conclusion in the reduction of fall events. The tailored interventions present an opportunity for offering more education and training, closing the identified gaps or barriers found during the entire process of project implementation, and evaluating to find alternatives to educate family and engage them in the planned intervention.

\section{Limitations}

The study was limited by the short period of education and training. The original plan to give nurses an hour of paid training was not approved due to budget constraints. The telemetry educator provided the training during their "downtime" but was not able to train all telemetry staff because of the COVID-19 pandemic. Additionally, the DNP project leader found out that nurses scored poorly on the "patient and family education on tailored intervention" audit. Due to the COVID-19 pandemic, there were no visitors allowed during the project implementation. 
Education could have been provided during admission when fall assessment is usually initiated. Furthermore, instead of no education being documented or given, family members should have been educated via a phone call. Patient engagement on the tailored intervention should be added on the audit tool to supplement patient and family engagement, to get more precise results. Another limitation was the inconsistent use of the universal fall precaution supplies due to the availability of supplies. During the audit, the telemetry unit ran out of yellow gowns and yellow socks although nurses are aware of the universal fall supplies and used red nonskid socks on their patients instead. On the audit, these patients were marked wearing yellow socks. The next concern was the budget constraints. The DNP project leader faced challenges on the education and training on fall and tailored intervention and fall posters inside the telemetry room. The original plan of paying nurses for an hour of training was not approved due to budget constraints. In addition, the plan to print and use $12 \times 20$ posters as recommended was not granted. The $8 \mathrm{x}$ 12 posters were too small, and most patients verbalized that the posters were too small and too hard to see from the bed, so the patients were not able to identify their risk and intervention. To promote patient safety, the limitations, barriers, and opportunities were shared with the director and clinical coordinator so that corrective actions could be taken and to close the specific gaps in fall prevention.

\section{Implications}

Falls in hospitalized patients are a pressing safety concern in the organization because of unreimbursed costs of fall-related injury, which range from $\$ 7000-\$ 30,000$ depending on the severity of the injury (Spetz, Brown \& Adin, 2015). According to Agency Healthcare Research and Quality (AHRQ), falls are preventable injuries which can cost an estimated $\$ 700,000$ to $\$ 1,000,000$ for hospitalized patient falls annually (AHRQ, 2015a). It is imperative for nurses to 
implement the fall assessment with tailored interventions by educating patients on the specific fall interventions to promote patient safety and prevent falls. Structured educational material that will include fall risk assessment with tailored intervention and universal fall precautions should be a standard of care for adult patients admitted in the telemetry unit who have a Morse Fall Score of low risk, medium risk or high risk.

\section{Project Dissemination}

\section{Internal Dissemination}

The presentation of the EBP project was scheduled on July 14, 2020, during one of the bi-weekly quality patient safety meetings of directors. The stakeholders present were the risk management director, quality director, some of the unit department directors, and their clinical coordinators. Due to the COVID-19 pandemic, the presentation of the fall assessment with tailored intervention results was conducted through a virtual meeting. The DNP project leader used a PowerPoint poster and delivered the quality improvement project results for 10 to15 minutes. The poster presented the significance of practice problem, the PICOT question, practice recommendation, project overview, evaluation, results, implications and conclusions. In addition, the project results were also presented to the telemetry unit staff and to the champions on July 20, 2020.

The DHR Health Institute and research scientist also planned to present this project's results to the trauma unit staff and stakeholders. No final approval has yet been received from the neurosurgeons and directors because of the pandemic, but it is anticipated. According to Siedlecki, Montague, and Schultz (2008), information should be disseminated at the institutional level before it is disseminated to the public to prevent ethical pitfalls. 


\section{External Dissemination}

According to White, Dudley-Brown, and Terhaar (2016), dissemination is an essential part of the translation of evidence. Edward (2015) noted it is also an important step toward practice change. For the external dissemination, the three main methods (poster, presentation, and manuscript or paper) can be used. Each method requires structure and has specific requirements for publication. The DNP scholarly paper was initially published to the University of St. Augustine for Health Sciences' an institutional repository, called SOAR@USA, which is available in the USAHS Library. The full text scholarly paper was also submitted to Henderson Library on August 5, 2020.

The DNP project leader is also a member of the National League of Nursing (NLN), she plans to present the scholarly paper through a poster. First, she must submit an abstract for leadership review in order to be approved for presentation-at the NLN Summit in Florida on September 26-30, 2020. If approved, the presentation will incorporate the framework model Nursing Process for Fall Assessment and Intervention. However, the NLN Summit may be cancelled or held remotely due to COVID-19.

The DNP project leader would also like to publish her project in The Joint Commission Journal of Quality and Patient Safety. The project is appropriate to be published in this journal because this journal: "is dedicated to providing new ideas and information to improve the quality and safety of healthcare" (JCJQPS, 2019, p.3). Subsequently, the DNP project leader followed the journal's guidelines for manuscript submission: the text was limited to 4000 words and organized into Introduction, Methods, Results, and Discussion (JCJQPS, 2019, p.4). As part of the publication decision process, the submitted manuscript will be subjected to peer review. 


\section{Conclusion}

The Fall Assessment with Tailored Intervention for adult patients in the telemetry unit showed clinically and statistically significant results in decreasing fall events within a 12 -week period. The DNP project leader found that the Morse Fall Assessment showed clinically and statistically significant results in decreasing the fall rate over 12 weeks with an average of 2.47 /1000 patient days, which is below national benchmark. In addition, there were no injuries for all the fall events. Dykes et al. (2017), Ambutas (2017), and Johnston and Magnan (2019) concluded that the use of a fall risk assessment tool can help in the process of tailoring patientcentered interventions. Moreover, using a fall risk assessment as the first step of intervention and arriving at a fall risk score by knowing the risk factors can mitigate the risk and successfully implement fall interventions. The findings support the conclusion that the Morse Fall Assessment can be used as an assessment tool to apply specific tailored interventions to promote patient safety and prevent falls.

\section{Results}

The Agency for Healthcare Research and Quality (AHRQ, 2013) has recommended that falls be measured as a rate to account for the unit's census at a given time. Therefore, the fall rate was calculated based on the NDNQI recommendation, which is the number of fall incidences occurring in a month divided by the total number of occupied beds for the same month, multiplied by 1000 (AHRQ, 2013); There was a decrease in the rate of fall for the month of February, which was 2.29/1000 days' patient days, and March, which was $1.77 / 1000$ patient days. The April fall rate increased tremendously from 1.77/1000 patient days to 4.75/ 1000 patient days. The month of May fall rate was $1.74 / 1000$ patient days. The average monthly fall rate over 12-week implementation period was $2.47 / 1000$ patient days, which was below the 
national benchmark of 3.44/1000 patient days. The fall assessment documentation in two telemetry units at DHR Health can be adapted or implemented hospital-wide. The results showed a statistically significant correlation between the Morse fall score assessment on EHR and monthly fall events $(p=0.0078)$.

The primary strength of implementing the Morse Fall Assessment with Tailored Intervention was its collaborative approach and the teamwork encountered during the implementation and evaluation, despite the unprecedented event of COVID-19. Another strength is the Morse Fall Assessment compliance on EHR and treating all patients as risk to fall. Also, EHR power form with tailored intervention is part of daily assessment that is available in the nursing care plan. In addition, nurses have high compliance on use of call lights, fall signage on the wall, and placing bed at lowest position. Also, the nurse coordinator, who used the tailored intervention poster, found it is easy to read, apply, and understand. Involving family members in the fall prevention plan targeted to patient specific fall risk has decreased fall rates during the first two months of implementation. The fall audit tool aids in the identification of variation to nursing practices that depart from clinical standards. Moreover, the clinical coordinators can therefore take corrective actions to address specific gaps in the tailored intervention to promote patient safety. 


\section{References}

Agency for Healthcare Research and Quality. (2015a). Preventing falls in hospitals: A toolkit for improving quality of care. Retrieved from http://www.ahrq.gov/professionals/systems/hospital/fallpxtoolkit.pdf

Agency for Healthcare Research and Quality HRQ. (2015b). Preventing falls in hospital: How do you calculate fall rate? Retrieved from http://www.ahrq.gov/professionals/systems/hospital/fallpxtoolkit.pdf

Ambutas, S. (2017). Continuous quality improvement. Fall reduction and injury prevention toolkit: Implementation on two medical-surgical units. MEDSURG Nursing, 26(3), 175197. Retrieved from http://search.ebscohost.com/login.aspx? direct $=$ true $\& \mathrm{db}=\mathrm{ccm} \& \mathrm{AN}=123430220 \&$ site $=$ eds-live

American Geriatric Society. (2010). AGS/BGS clinical practice guideline: Prevention of falls on older person. Retrieved from https://geriatricscareonline.org/Product Abstract/updated-american-geriatrics-societybritish-geriatrics-society-clinical-practiceguideline-for-prevention-of-falls-in-older-persons-andrecommendations/CL014/?param2=search

Ayton, D. R., Barker, A. L., Morello, R. T., Brand, C. A., Talevski, J., Landgren, F. S., . . Botti, M. (2017). Barriers and enablers to the implementation of the 6-PACK falls prevention program: A pre-implementation study in hospitals participating in a cluster randomized controlled trial. PLoS One, 12(2). http://dx.doi.org/10.1371/journal.pone.0171932

Barker, A. L., Morello, R. T., Ayton, D. R., Hill, K. D., Brand, C. A., Livingston, P. M., \& Botti,M. (2017). Acceptability of the 6-PACK falls prevention program: A pre- 
implementation study in hospitals participating in a cluster randomized controlled trial. PLoS ONE, (2). https://doi.org/10.1371/journal.pone.0172005

Boswell, D., Ramsey, J., Smith, M., \& Wagers, B. (2001). The cost-effectiveness of a patientsitter program in an acute care hospital: A test of the impact of sitters on the incidence of falls and patient satisfaction. Quality Management in Health Care, 10(1), 10-16. Retrieved from http://journals.lww.com/qmhcjournal/Abstract/2001/ 10010/The_Cost_Effectiveness_of_a_Patient_Sitter_Program.3.aspx

Brown, C. G. (2014). The Iowa model of evidence-based practice to promote quality care: An illustrated example in oncology nursing. Clinical Journal of Oncology Nursing, 18(2), 157-159. https://doi.org/10.1188/14.CJON.157-159

Buckwalter, K. C., Cullen, L., Hanrahan, K., Kleiber, C., McCarthy, A. M., Rakel, B., ... Tucker, S. (2017). Iowa model of evidence-based practice: Revisions and validation. Worldviews on Evidence-Based Nursing, 14(3), 175-182. https://doi.org/10.1111/wvn.12223

Burns, E. R., Stevens, J. A., \& Lee, R. (2016). The direct costs of fatal and non-fatal falls among older adults -United States. Journal of Safety Research, 58, 99-103. https://doi.org/10.1016/j.jsr.2016.05.001

Centers for Medicare and Medicaid Services.(2015) Hospital-acquired conditions. Retrieved from https://www.cms.gov/Medicare/Medicare-Fee-for-ServicePayment/HospitalAcqCond/Hospital-Acquired_Conditions.html

Clinical and performance safety metrics (2019). Nursing quality metrics. Retrieved from https://clinicalcenter.nih.gov/home/pdf/SafetyMetrics.pdf

Cost of falls among older adults. (2015). Retrieved from http://www.cdc.gov/Homeand 
RecreationalSafety/Falls/fallcost.html

Cuesta-Benjumea, C., Henriques, M. A., Abad-Corpa, E., Roe, B., Orts-Cortes, M. I., LidonCerezuela, B., ... Sanchez-Ardila, C. (2017). Falls prevention among older people and care providers: Protocol for an integrative review. Journal of Advanced Nursing, (7), 1722. https://doi.org/10.1111/jan.13245

Coussement,J., De Paepe,L., Schwendimann,R.,Denhaerynek, K.,Dejaeger, E., \& Millessen,K. (2008). Intervention for preventing falls in acute and chronic care hospital: A systematic review and meta- analysis. Journal of American Geriatric Society, 56(1), 29-36.

Dearholt, S. L., Dang, D., \& Philbrick, V. (2013). Johns Hopkins nursing evidence-based practice: Model and guidelines, 2nd edition: The official voice of perioperative nursing the official voice of perioperative nursing. AORN Journal, 97(1), 157-158. https://doi.org/10.1016/j.aorn.2012.10.004

DHR Health. (n.d ). About DHR health. Retrieved from https://dhrhealth.com/about DHR Health (2019). DHR health fall and slip event summary. Unpublished raw data.

Duckworth, M., Adelman, J., Belategui, K., Feliciano, Z., Jackson, E., Khasnabish, S., ... Dykes, P. C. (2019). Assessing the effectiveness of engaging patients and their families in the three-step fall prevention process across modalities of an evidence-based fall prevention toolkit: An implementation science study. Journal of Medical Internet Research, 21(1), e10008. https://doi.org/10.2196/10008

Dykes, P. C., Duckworth, M., Cunningham, S., Dubois, S., Driscoll, M., Feliciano, Z., ... Scanlan, M. (2017). Pilot testing fall TIPS (tailoring interventions for patient safety): A patient-centered fall prevention toolkit. The Joint Commission Journal on Quality and Patient Safety, 43(8), 403-413. https://doi.org/10.1016/j.jcjq.2017.05.002 
Dykes, P. C., Adelman, J. S., Alfieri, L., Bogaisky, M., Carroll, D., Carter, E., ... Spivack, L. B. (2019). The fall TIPS (tailoring interventions for patient safety) program: A collaboration to end the persistent problem of patient Falls. Nurse Leader, 17(4), 365-370. https://doi.org/10.1016/j.mnl.2018.11.006

Ebben, R. H. A., Vloet, L. C. M., Schalk, D. M. J., Mintjes-de Groot, J. A. J., \& van Achterberg, T. (2014). An exploration of factors influencing ambulance and emergency nurses' protocol adherence in the Netherlands. Journal of Emergency Nursing, 40(2), 124-130. https://doi.org/10.1016/j.jen.2012.09.008

Galbraith, J. G., Butler, J. S., Memon, A. R., Dolan, M. A., \& Harty, J. A. (2011). Cost analysis of a falls-prevention program in an orthopaedic setting. Clinical orthopaedics and Related Research, 469(12), 3462-3468. https://doi.org/10.1007/s11999-011-1932-9

Graphpad. (n.d). Introducing Prism 8. Retrieved from https://www.graphpad.com/scientific-software/prism/

Johnston, M. \& Magnan, M. A. (2019). Using a fall prevention checklist to reduce hospital falls. AJN, American Journal of Nursing, 119(3), 43-49. https://doi: 10.1097/01.NAJ.0000554037.76120.6a.

John Hopkins University. (n.d.). The John Hopkins nursing evidence-based practice.

Retrieved from https://www.hopkinsmedicine.org/evidence-basedpractice/_docs/appendix_c_evidence_level_quality_guide.pdf

Joint Comission. (2015). Sentinel event 55: Preventing falls and fall-related injuries in health care facilities. Retrieved from http://12.167.4.172//media/tjc/documents/resources/patient-safety-topics/sentinelevent/sea_55_falls_4_26_16.pdf 
Laycock, A., Bailie J.,Matthews,V., \& Ross Bailie. (2019). Using developmental evaluation to support knowledge translation: Reflections from a large-scale quality improvement project in Indigenous primary healthcare. Health Research Policy and Systems, (1), 1. https://doi.org/10.1186/s12961-019-0474-6

Laws, D., \& Crawford, C. (2013). Alternative strategies to constant patient observation and sitters. Journal of Nursing Administration, 43, 497-501. http://dx.doi.org/10.1097/NNA.0b013e3182a3e83e

LeLaurin, J. H., \& Shorr, R. I. (2019). Preventing falls in hospitalized patients: State of the science. Clinics in Geriatric Medicine, 35(2), 273-283. https://doi.org/10.1016/j.cger.2019.01.007

Massoud M., Nielsen G.A., Nolan K, Schall MW, Sevin C. (2006). A framework for spread: From local improvements to system-wide change. Retrieved from http://www.ihi.org/resources/Pages/IHIWhitePapers/AFrameworkforSpreadWhitePaper.a $\operatorname{spx}$

Madeline, J., \& Morris A.M. (2019). Using a fall prevention checklist to reduce hospital falls: Results of a quality improvement project. AJN, American Journal of Nursing, (3), 43. https://doi.org/10.1097 /01.NAJ.0000554037.76120.6

Meddings J.A., \& McMahon, L.F. (2008). Measuring quality in pay-per-performance programs: From "one-size-fits- all” measures to individual patient risk-reduction scores. Disease Management \& Health Outcomes, 16(4), 205-216. Retrieved from http://search.ebscohost.com/login.aspx?direct=true\&db=ccm\&AN=105665290\& site=eds-live

Melin, C. M. (2018). Reducing falls in the inpatient hospital setting. International Journal Of 
Evidence-Based Healthcare, 16(1), 25-31. https://doi.org/10.1097/XEB.

0000000000000115

Melnyk, B.M., Fineout-Overholt, E., Gallagher-Ford, L., \& Kaplan, L. (2012). The state of evidence-based practice in US nurses: Critical implications for nurse leaders and educators. Journal of Nursing Ad-ministration, 42, 410-417.

doi:10.1097/NNA.0b013e3182664e0a

Nolan, K., Schall, M. W., Erb, F., \& Nolan, T. (2005). Using a framework for spread: The case of patient access in the veterans health administration. The Joint Commission Journal on Quality and Patient Safety, 31(6), 339-347. https://doi.org/10.1016/S1553$7250(05) 31045-2$

Patient Safety Authority ( n.d.). Fall prevention process measure audit tool. Retrived from http://patientsafety.pa.gov/pst/Pages/Falls/audit.aspx

Ryan, P. L., Mamaril, M., \& Shope, B. (2017). The Johns Hopkins evidence based practice (EBP) model: Learning the process and appraising the evidence. Journal of PeriAnesthesia Nursing, (4), 29. https//doi.org/10.1016/j.jopan.2017.06.098

Spetz, J., Brown, D., \& Adin, C. (2015). The economics of preventing hospital falls. Journal of Nursing Administration, 45, 50-57. https://doi.org/10.1097/NNA.0000000000000154

Spiva, L., Feiner, T., Jones, D., Hunter, D., Petefish, J., \& VanBrackle, L. (2012). An evaluation of a sitter reduction program intervention. Journal of Nursing Care Quality, 27, 341-345. http://dx.doi.org/doi:10.1097/NCQ.0b013e31825f4a5f

Titler, M. G., Conlon, P., Reynolds, M. A., Ripley, R., Tsodikov, A., Wilson, D. S., \& Montie, M. (2016). The effect of a translating research into practice intervention to promote use of evidence-based fall prevention interventions in hospitalized adults: A prospective pre- 
post implementation study in the U.S. Applied Nursing Research, 31, 52-59. https://doi.org/10.1016/j.apnr.2015.12.004

Tzeng, H., \& Yin, C. (2015). Patient engagement in hospital fall prevention. Nursing Economics, 33(6), 326-334. Retrieved from https://search.proquest.com/ docview/1750045067? accountid=7069

Wong, C. A., Recktenwald, A. J., Jones, M. L., Waterman, B. M., Bollini, M. L., \& Dunagan, W. C. (2011). The cost of serious fall-related injuries at three Midwestern hospitals. Joint Commission Journal on Quality and Patient Safety, 37(2), 81-87. https://doi.org/10.1016/s1553-7250(11)37010-9 
Figure 1.

IHI Framework for Spread

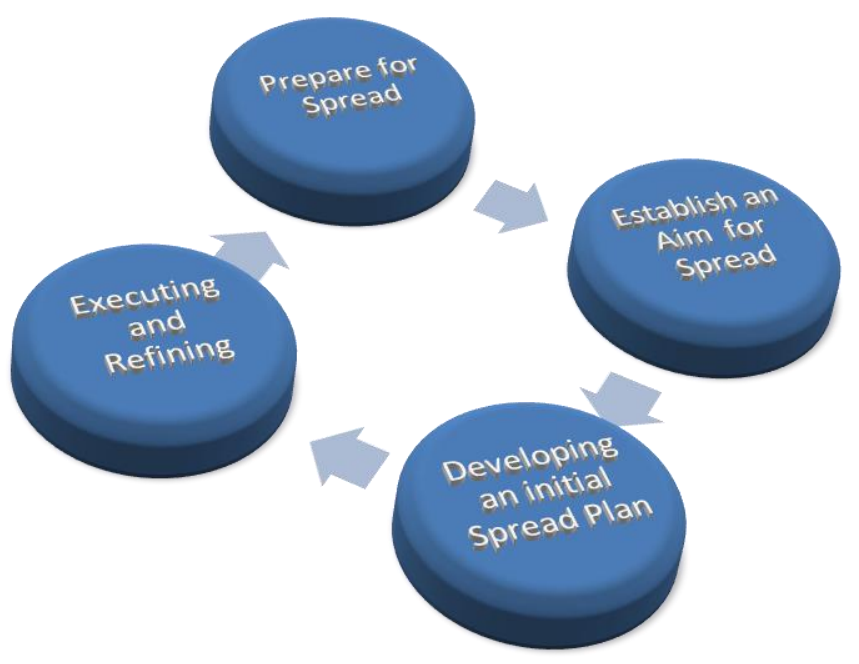




\section{Appendix A}

\section{PRISMA 2009 Flow Diagram}
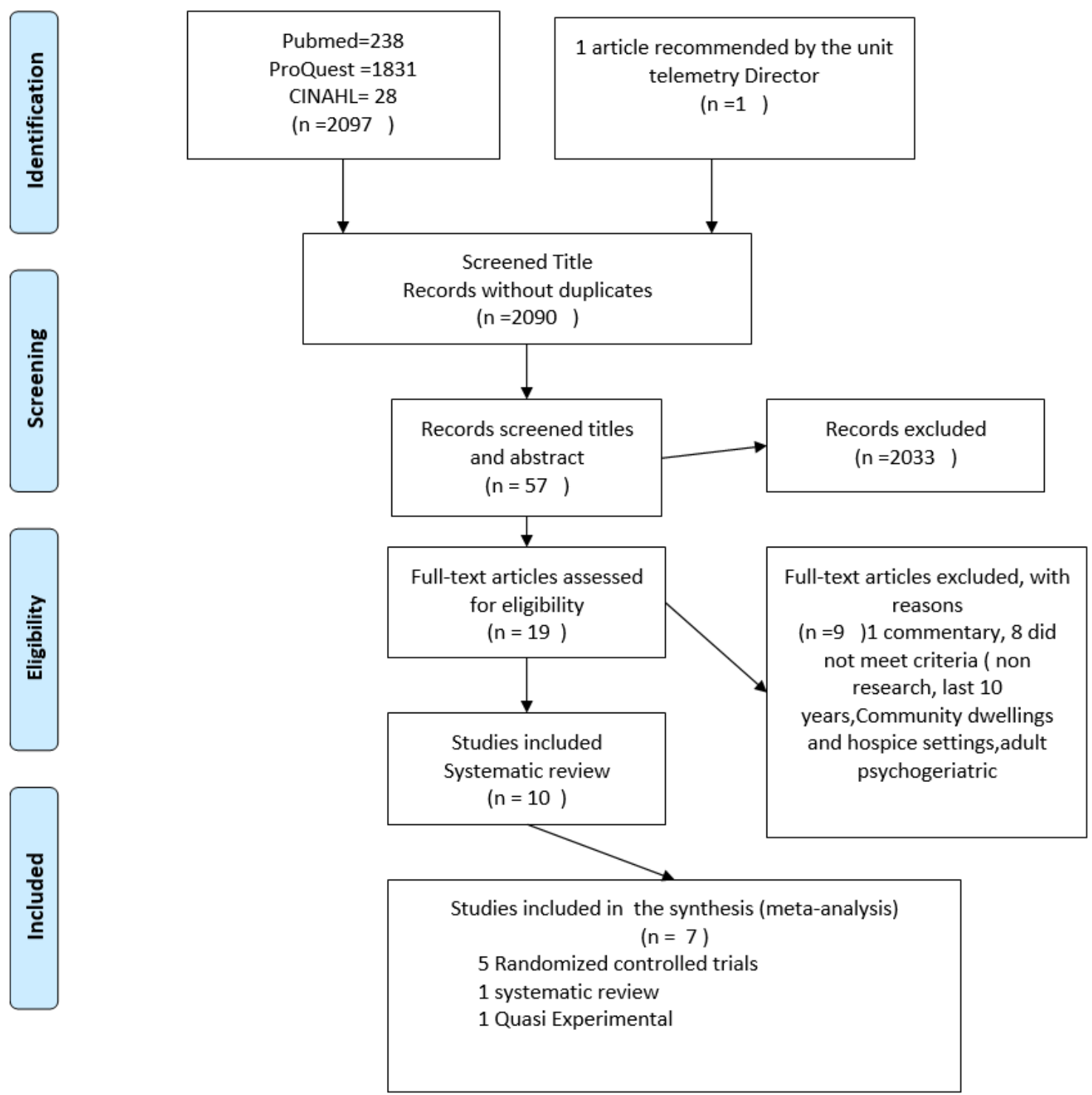

From: Moher D, Liberati A, Tetzlaff J, Altman DG, The PRISMA Group (2009). Preferred Reporting /tems for Systematic Reviews and MetaAnalyses: The PRISMA Statement. RheS Med 6(6): e1000097. doi:10.1371/iquwhahowed1000097 


\section{Appendix B}

\section{Summary of Primary Research Evidence}

\begin{tabular}{|c|c|c|c|c|c|c|}
\hline Citation & $\begin{array}{c}\text { Design, Level } \\
\text { Quality } \\
\text { Grade }\end{array}$ & $\begin{array}{c}\text { Sample } \\
\text { Sample size }\end{array}$ & $\begin{array}{c}\text { Intervention } \\
\text { Comparison } \\
\text { (Definitions should } \\
\text { include any specific } \\
\text { research tools used along } \\
\text { with reliability \& } \\
\text { validity) }\end{array}$ & $\begin{array}{l}\text { Theoretical } \\
\text { Foundation }\end{array}$ & Outcome Definition & $\begin{array}{l}\text { Usefulness } \\
\text { Results } \\
\text { Key Findings }\end{array}$ \\
\hline $\begin{array}{l}\text { Ambutas, } 2017 \text { Fall Reduction } \\
\text { and Injury Prevention Toolkit: } \\
\text { Implementation on Two } \\
\text { Medical-Surgical Units }\end{array}$ & $\begin{array}{l}\text { Meta-analysis } \\
\text { with RCT } \\
\text { Level I } \\
\text { Grade A }\end{array}$ & $\begin{array}{l}\text { 664-bed academic } \\
\text { medical center in } \\
\text { Chicago, IL. } \\
\text { Unit } 1 \text { is a 32-bed } \\
\text { neurology/neurosurgery } \\
\text { medical-surgical unit. } \\
\text { Unit } 2 \text { is a } 32 \text {-bed } \\
\text { general medical unit. }\end{array}$ & $\begin{array}{l}\text { The AHRQ program toolkit used } \\
\text { educational programs and leader } \\
\text { support, and included fall team } \\
\text { member audits to ensure } \\
\text { implementation. The project } \\
\text { director provided a fall specific } \\
\text { standard of care audit tool. The } \\
\text { process for implementing the fall } \\
\text { toolkit was planned over a year, } \\
\text { and implemented within } 6 \\
\text { months. Promotion included use } \\
\text { of Call Don't Fall signs in patient } \\
\text { rooms, Fall No More buttons, } \\
\text { and } 10 \text { Steps to Keep Your } \\
\text { Patient Safe } \\
\text { Establishing an interprofessional, } \\
\text { individualized care plan may help } \\
\text { prevent future falls. }\end{array}$ & $\begin{array}{l}\text { The Rush Way } \\
\text { CQI model } \\
\text { used for this } \\
\text { project is based } \\
\text { on the Lean } \\
\text { Six Sigma } \\
\text { methodology } \\
\text { as well as } \\
\text { recognition } \\
\text { CQI }\end{array}$ & $\begin{array}{l}\text { Pre and Post study } \\
\text { Outcome indicators for this } \\
\text { QI project were falls with } \\
\text { and falls without injury per } \\
1,000 \text { patient days. } \\
\text { Improve staff knowledge of } \\
\text { fall reduction measures, } \\
\text { particularly those to reduce } \\
\text { injury, as evidenced by test } \\
\text { score greater than } 90 \% \text {. } \\
\text { Reduce falls with injury to } \\
\text { less than } 0.3 \text { per } 1,000 \\
\text { patient days on study units. } \\
\text { Reduce falls without injury } \\
\text { on study units to less than } \\
3.4 \text { per } 1,000 \text { patient days. } \\
\text { Unit } 1,81 \text { falls were } \\
\text { documented in } 2013 \text {. Falls } \\
\text { from bed had the highest } \\
\text { frequency ( } 40 \%, n=73 \text { ), } \\
\text { followed by falls related to } \\
\text { toileting or commode usage } \\
\text { (27\%, n=22) } \\
\text { Unit } 2,54 \text { falls were } \\
\text { documented. Of } 38 \text { falls } \\
\text { related to toileting ( } 70 \% \text {, } \\
\text { seven involved injuries (six } \\
\text { minors, one major) } \\
\text { Changes in falls and fall } \\
\text { with injury per } 1000 \text { patient } \\
\text { days. }\end{array}$ & $\begin{array}{l}\text { Interprofessional individualized care plan } \\
\text { and post-fall huddle included patients and } \\
\text { families. Can prevent fall } \\
\text { Project goals were achieved through leader } \\
\text { support and promotion of staff } \\
\text { accountability. Staff were involved in } \\
\text { problem analysis, fall toolkit } \\
\text { implementation, ongoing review of falls, } \\
\text { and continual evaluation of the process. } \\
\text { The organization's safety climate } \\
\text { improved as staff became accountable for } \\
\text { reducing falls and preventing injury. } \\
\text { Opportunities for interprofessional } \\
\text { education were addressed by the project } \\
\text { director at various department meetings. } \\
\text { Continued mentoring by fall team } \\
\text { members and unit leaders, confirming the } \\
\text { importance of organizational systems. } \\
\text { The infrastructure and capacity to identify } \\
\text { and address solutions for patients were } \\
\text { successful because of unit champions' } \\
\text { diligence and continual feedback } \\
\text { Fall decreased from } 7.98 \text { to } 6.6 / .23 .8 \% \\
\text { improvement on the fall rate }\end{array}$ \\
\hline
\end{tabular}




\begin{tabular}{|c|c|c|c|c|c|c|}
\hline & & & & & $\begin{array}{l}\text { Baseline Unit } 1: 7.98 \text { fall; } \\
\text { Fall with injury } 0.68 \\
\text { Post toolkit interventions: } \\
\text { Fall rate } 6.6 \\
\text { Fall with injury } 0.53 \\
\text { Baseline Unit } 2 \text {; falls } 4.8 \text {; } \\
\text { fall with injury } 0.94 \\
\text { Post toolkit interventions: } \\
\text { Falls } 4.5 \\
\text { Fall with injury } 0.19\end{array}$ & \\
\hline $\begin{array}{l}\text { Ayton et al., (2017) Barrier and } \\
\text { Enabler to the implementation } \\
\text { of the PACK fall prevention } \\
\text { Program: A pre-implementation } \\
\text { study in hospitals participating } \\
\text { in a cluster randomized } \\
\text { controlled Trials }\end{array}$ & $\begin{array}{l}\text { Level I } \\
\text { Randomized } \\
\text { controlled trial } \\
\text { Grade A }\end{array}$ & $\begin{array}{l}\text { Multi -Centre Mixed } \\
\text { method Study (3-year } \\
\text { research plan) } \\
16 \text { medical and } 8 \\
\text { surgical wards } \\
\text { Survey response rate = } \\
60 \% \text { (420/702), and } 12 \\
\text { focus group (n=96 } \\
\text { nurses) and 24 } \\
\text { interviews }\end{array}$ & $\begin{array}{l}\text { Intervention: Nurse Survey } \\
42 \text { item nurse survey was } \\
\text { developed to assess beliefs about } \\
\text { falls; current fall prevention } \\
\text { practices. } 6 \text { PACK program (fall } \\
\text { alert sign, supervision in the } \\
\text { restroom, walking aids within } \\
\text { reach, toileting regime, low bed, } \\
\text { bed and chair alarm) } \\
\text { components, best practices } \\
\text { guidelines key recommendations; } \\
\text { and reporting practices were } \\
\text { included. A 5-point Likert scale } \\
\text { was used. } \\
\text { Descriptive statistics were } \\
\text { calculated for survey response } \\
\text { using Stata MP v } 13 \text { statistical } \\
\text { software. Quantitative and } \\
\text { qualitative with triangulation. } \\
\text { Survey response rate = } 60 \% \\
\text { (420/702), and } 12 \text { focus group } \\
\text { (n=96 nurses) and } 24 \text { interviews }\end{array}$ & $\begin{array}{c}\text { COM- B } \\
\text { framework that } \\
\text { includes three } \\
\text { behavior } \\
\text { change } \\
\text { construct of: } \\
\text { Capability, } \\
\text { opportunity } \\
\text { and } \\
\text { Motivation) }\end{array}$ & $\begin{array}{l}\text { Pre-post implementation } \\
\text { study with } 60 \text { percent } \\
\text { response rate } \\
\text { Nurse survey } 720 \\
12 \text { focus group } \\
24 \text { interviews } \\
\text { Response rate }=420(60 \%)\end{array}$ & $\begin{array}{l}\text { The study identified barrier and enablers } \\
\text { to the implementation of } 6 \text { PACK } \\
\text { program. } \\
\text { Barrier identified: beliefs that fall cannot } \\
\text { be prevented, limited knowledge on fall } \\
\text { prevention, and lack of ownership. } \\
\text { Enablers: education and training, } \\
\text { improved leadership, use of data to drive } \\
\text { practice change, use of reminders, audits } \\
\text { and feedback. The need to have leaders } \\
\text { and champions. } \\
\text { The recommendation on how to tackle } \\
\text { barriers will be helpful to close the gaps } \\
\text { on the implementation. } \\
\text { Stakeholders response and suggestion to } \\
\text { address barriers will be helpful in the } \\
\text { sustainability of the quality improvement } \\
\text { project. }\end{array}$ \\
\hline $\begin{array}{l}\text { Barker, Morello, Ayton, Hill, } \\
\text { Brand and Livingston (2017) } \\
\text { Acceptability of } 6 \text { PACK fall } \\
\text { prevention program: A pre- } \\
\text { implementation study in } \\
\text { hospitals participating in a } \\
\text { cluster randomized controlled } \\
\text { trial }\end{array}$ & $\begin{array}{l}\text { Level IV } \\
\text { Clinical practice } \\
\text { Guidelines } \\
\text { Grade A }\end{array}$ & $\begin{array}{l}\text { Multi Centre mixed } \\
\text { method with COREQ } \\
\text { guidelines (3-year } \\
\text { research plan) } \\
24 \text { acute wards }\end{array}$ & $\begin{array}{l}\text { Intervention: Nurse Survey } \\
42 \text { item nurse survey was } \\
\text { developed to assess beliefs about } \\
\text { falls; current fall prevention } \\
\text { practices. } 6 \text { PACK program } \\
\text { components, best practices } \\
\text { guidelines key recommendations; } \\
\text { and reporting practices were } \\
\text { included. A 5-point Likert scale } \\
\text { was used. } \\
\text { Descriptive statistics were } \\
\text { calculated for survey response } \\
\text { using Stata MP v } 13 \text { statistical } \\
\text { software. Quantitative and } \\
\text { qualitative with triangulation. } \\
\\
\text { Survey response rate }=60 \% \\
(420 / 702) \text {, and } 12 \text { focus group } \\
\text { (n=96 nurses) and } 24 \text { interviews }\end{array}$ & $\begin{array}{l}\text { No framework } \\
\text { mentioned }\end{array}$ & $\begin{array}{l}\text { Pre-implementation study } \\
\text { with } 60 \text { percent response } \\
\text { rate } \\
\text { Nurse survey } 720 \\
12 \text { focus group } \\
24 \text { interviews } \\
\text { Response rate }=420(60 \%)\end{array}$ & $\begin{array}{l}\text { 6- PACK program was suitable with high } \\
\text { levels of demands for a new fall } \\
\text { prevention approach. } \\
\text { Concepts identified in the domain: } \\
\text { 1. Integrated care plan with daily } \\
\text { nurse review } \\
\text { 2. Fall risk tool } \\
\text { 3. Alert sign } \\
\text { 4. Bathroom supervision } \\
\text { 5. Patient walking aids within } \\
\text { reach } \\
\text { 6. Toileting regimes } \\
\text { 7. Low beds/ chair alarms } \\
\text { 8. Bed alarms } \\
\text { The study confirmed acceptability of the } 6 \\
\text { PACK program / Nurses perceived that the } \\
\text { program is suitable, practical and } \\
\text { beneficial ways to reduce falls. }\end{array}$ \\
\hline
\end{tabular}




\begin{tabular}{|c|c|c|c|c|c|c|}
\hline & & & & & & $\begin{array}{l}\text { The survey has recommendation regarding } \\
\text { barriers to the } 8 \text { items listed. Applying } \\
\text { those recommendation on the conceptual } \\
\text { model will be beneficial. }\end{array}$ \\
\hline $\begin{array}{l}\text { Cuesta-Benjumea et al., (2017) } \\
\text { Fall prevention among older } \\
\text { people and care providers: } \\
\text { protocol for an integrative } \\
\text { review }\end{array}$ & $\begin{array}{l}\text { Design: Non- } \\
\text { experimental } \\
\text { Systematic review } \\
\text { Level: III } \\
\text { Quality: B }\end{array}$ & $\begin{array}{l}\text { Articles from } \\
\text { CINAHL, PUBMED, } \\
\text { JBI, COCHRANE, } \\
\text { WEB OF SCIENCE, } \\
\text { OPEN GREY, } \\
\text { MEDES, LILACS, } \\
\text { TESEO, } \\
\text { DISSERTATION } \\
\text { ABSTRACT, THESIS } \\
\text { PROCEEDINGS, } \\
\text { Psych INFO and } \\
\text { EMBAS }\end{array}$ & $\begin{array}{l}\text { Integrative review to identify } \\
\text { appraise and synthesize evidence } \\
\text { of the role of the care provider on } \\
\text { fall preventions and its } \\
\text { interventions } \\
\text { Comparison: } \\
\text { Usual care or supportive fall } \\
\text { preventive comparators. } \\
\\
\text { Reliability and Validity: } \\
\text { Adherence to the PRISMA } \\
\text { statement checklist and } \\
\text { ENTEREQ framework }\end{array}$ & None & $\begin{array}{l}\text { Analyze and synthesize } \\
\text { qualitative and quantitative } \\
\text { studies } \\
\text { Synthesize description of } \\
\text { intervention and roles played } \\
\text { by care providers. }\end{array}$ & $\begin{array}{l}\text { Assessment and prevention are the key } \\
\text { recommendation as a key best practice for } \\
\text { fall prevention. } \\
\text { Involvement of healthcare professionals } \\
\text { such family, doctor, nurses and } \\
\text { occupational therapist. } \\
\text { Evidence shows the need to have a policy } \\
\text { and need to be interpreted in context with } \\
\text { local evidence. }\end{array}$ \\
\hline $\begin{array}{l}\text { Duckworth et al, } 2019 . \\
\text { Assessing the effectiveness of } \\
\text { engaging patients and their } \\
\text { families in the three - step fall } \\
\text { prevention process across } \\
\text { modalities of an evidence- } \\
\text { based toolkit: An } \\
\text { implementation Science study }\end{array}$ & $\begin{array}{l}\text { Level IV } \\
\text { Clinical practice } \\
\text { guidelines } \\
\text { Grade A }\end{array}$ & $\begin{array}{l}1209 \text { audits were } \\
\text { submitted for patient } \\
\text { engagement measures. } \\
1401 \text { Presence of poster } \\
\text { at the bedside. }\end{array}$ & $\begin{array}{l}\text { Three modalities: } \\
\text { Laminated Fall TIPS toolkit } \\
\text { Electronic Fall tips Toolkit } \\
\text { Patient safety display of Fall } \\
\text { TIPS }\end{array}$ & None & $\begin{array}{l}80 \% \text { engagement on the fall } \\
\text { tips toolkit and display of } \\
\text { posters. } \\
>80 \% \text { adherence after one } \\
\text { month on both protocols }\end{array}$ & $\begin{array}{l}\text { The three TIPS modalities are an effective } \\
\text { and flexible approach for promoting } \\
\text { adoption and spread. }\end{array}$ \\
\hline $\begin{array}{l}\text { Dykes et al.,2017 } \\
\text { Pilot Testing for TIPS: A } \\
\text { patient centered fall prevention } \\
\text { toolkit. }\end{array}$ & $\begin{array}{l}\text { Level I } \\
\text { Randomized } \\
\text { controlled trial } \\
\text { Grade A }\end{array}$ & $\begin{array}{l}\text { Pilot Study } \\
4 \text { hospitals more than } \\
10 \text { thousand patients }\end{array}$ & $\begin{aligned} & \text { Three step process: } \\
& \text { 1. } \text { Fall assessment } \\
& \text { 2. } \text { Personalized fall } \\
& \text { prevention plan } \\
& \text { 3. } \text { Universal precaution } \\
& \text { with consistent fall } \\
& \text { implementation } \\
& \text { Comparison: } \\
& \text { Multiple fall interventions }\end{aligned}$ & $\begin{array}{l}\text { IHI Framework } \\
\text { for Spread } \\
\text { (Rogers } \\
\text { Classic } \\
\text { Diffusion } \\
\text { research) }\end{array}$ & $\begin{array}{l}\text { Pre and Post Patient Survey } \\
\text { (Qualitative research) } \\
\text { Protocol rate adherence } \\
\text { Patient fall rate } \\
\text { Patient fall related Injury } \\
\text { rate } \\
\text { Pre and Post Patient surveys } \\
\text { (Mann Whitney U test) } \\
\text { Identify fall risk: } \\
\text { Pre }=\mathrm{P}=3.7 \\
\text { Post }=\mathrm{P}=0.31 \\
\text { Knowledge to prevent fall } \\
\text { Pre= } \mathrm{P} 0.24 \\
\text { Post }=\mathrm{P}=0.001 \\
\\
\text { Protocol Adherence: Mean } \\
\text { adherence } 82 \% \\
\text { Patient fall rate }=3.28 \text { to } \\
2.80 / 1000 \text { days } \\
\text { Fall Non-tailored related } \\
\text { injury rate }=1.0 \text { to } 0.54\end{array}$ & $\begin{array}{l}\text { Leadership support to sustain fall. } \\
\text { Framework will maintain toolkit adoption, } \\
\text { sustain evidence fall prevention and } \\
\text { prevent falls } \\
\text { The use of a framework to address barriers } \\
\text { is a framework for improvement } \\
\text { Results: BWH hospital More than } 80 \\
\text { percent Adherence to the toolkit. Mean fall } \\
\text { rate decreased from } 3.28-2.80 \text { per } 1000 \\
\text { patient days Jan to June } 2015 \text { versus } 2016 \\
\text { MMC hospital toolkit compliance } \\
\text { averaged to } 91 \% \text { mean fall injury rate } \\
\text { decreased from } 0.47 \text { to } 0.31 \text { per } 1000 \\
\text { patient days } \\
\text { Patient survey shows improvement in } \\
\text { patient knowledge. } \\
\text { This pilot study is a reasonable evidence } \\
\text { based- practice intervention. }\end{array}$ \\
\hline
\end{tabular}




\begin{tabular}{|c|c|c|c|c|c|c|}
\hline $\begin{array}{l}\text { Johnston and Magnon (2019) } \\
\text { Using a Fall Prevention } \\
\text { checklist to reduce hospital fall: } \\
\text { Results of a Quality } \\
\text { improvement project }\end{array}$ & $\begin{array}{l}\text { Level II } \\
\text { Quasi } \\
\text { experimental } \\
\text { Grade C }\end{array}$ & $\begin{array}{l}\text { Pilot study (Feb- } \\
\text { march, 2018) } 26 \text { day } \\
\text { fall initiative } \\
37 \text { nursing staff } \\
\text { participated in the pilot } \\
\text { study and completed } 90 \\
\text { fall prevention } \\
\text { checklists. } \\
19 \% \text { of the time the bed } \\
\text { alarm is missed. } \\
\text { No patient falls during } \\
\text { study } \\
\text { (RN, CNA) } \\
84 \text { beds hospital }\end{array}$ & $\begin{array}{l}\text { The use of } 14 \text { checklist fall } \\
\text { intervention as a change of shift } \\
\text { report to determine if all } \\
\text { interventions were carried out or } \\
\text { in place. } \\
\text { 1.use of Schmid fall assessment } \\
\text { 2. use of assistive assessment } \\
\text { 3.Room signage } \\
\text { 4.fall wristband } \\
\text { 5. Nonskid foot wear } \\
\text { 6. call light within reach } \\
\text { 7.personal item within reach } \\
\text { 8.hourly rounding } \\
\text { 9.educate patient } \\
\text { 10. inform staff } \\
\text { 11. bed alarm } \\
\text { 12. educate Family } \\
\text { 13. hall way signage } \\
\text { 14.bed in lowest position } \\
\text { Comparison: no checklist only } \\
\text { approved hospital falls } \\
\text { prevention protocol. }\end{array}$ & No Framework & $\begin{array}{l}\text { Adherence rate on the fall } \\
\text { checklist prevention } \\
\text { Incidence of fall rate } \\
\text { Usefulness of the } \\
\text { intervention by doing } \\
\text { Checklist evaluation. (14 } \\
\text { participants out of } 37 \\
\text { completed and evaluation) }\end{array}$ & $\begin{array}{l}\text { Among the } 90 \text {-fall prevention checklist } \\
\text { completed: } \\
18 \%(\mathrm{n}=17 \text { ) bed alarm not set on zone } 2 \\
78 \% \text { believed that the checklist should be } \\
\text { use by everyone (RN and CNA). } \\
100 \% \text { believe that checklist is a good } \\
\text { safety check and it's easy to use and added } \\
\text { value to reduce falls } \\
\text { The pilot help to identify } 2 \text { common errors } \\
\text { (signage and alarm not activated to Zone } \\
\text { 2) } \\
\text { Sharp decline on fall incidence (pilot study } \\
\text { Feb- March 2018) } \\
\text { Check organization one size fits all } \\
\text { approach on fall interventions. Small } \\
\text { number of observation and short period of } \\
\text { time. }\end{array}$ \\
\hline Melin, ( 2018) & $\begin{array}{l}\text { Level I RCT with } \\
\text { Meta-analysis } \\
\text { Grade A }\end{array}$ & $\begin{array}{l}\text { Pilot study over 3- } \\
\text { month period. } 38 \text { beds } \\
\text { medical surgical unit at } \\
294 \text { bed community } \\
\text { hospital }\end{array}$ & $\begin{array}{l}\text { Utilizing the Morse Fall Scale, } \\
\text { and incorporating in the } \\
\text { intervention in the EHR using } \\
\text { universal fall precaution( yellow } \\
\text { arm band, and yellow signage, } \\
\text { skid proof socks, low bed. } \\
\text { the bed/chair alarm was } \\
\text { automatically activated for any } \\
\text { morse fall score of }>45 \text {. For } \\
\text { patients who did not fit these } \\
\text { criteria, nursing judgment was } \\
\text { still used to activate the bed/chair } \\
\text { alarm as needed. }\end{array}$ & $\begin{array}{l}\text { The Iowa } \\
\text { Model of } \\
\text { Evidence- } \\
\text { Based Practice } \\
\text { (EBP) was } \\
\text { used to guide } \\
\text { the } \\
\text { implementation } \\
\text { of this quality } \\
\text { improvement } \\
\text { project. The } \\
\text { model has } \\
\text { seven } \\
\text { components: } \\
\text { selection of a } \\
\text { topic, } \\
\text { formation of a } \\
\text { team, retrieval } \\
\text { of evidence, } \\
\text { grading of the } \\
\text { evidence, } \\
\text { development of } \\
\text { an EBP }\end{array}$ & $\begin{array}{l}\text { Pre and Post intervention } \\
\text { A comparison of the } \\
\text { preintervention and } \\
\text { postintervention data } \\
\text { showed a decrease in the } \\
\text { average monthly fall rate of } \\
3.6 \text { falls } / 1000 \text { patient days } \\
\text { and a } 44.5 \% \text { decrease in the } \\
\text { actual number of falls per } \\
\text { month. } \\
\text { The pilot unit had an } \\
\text { average monthly fall rate } \\
\text { during the preintervention } \\
\text { period of } 8.67 \text { falls } 1000 \\
\text { patient days, more than } \\
\text { double the national average } \\
\text { for a med-surg unit in the } \\
\text { United States of } 3.92 \\
\text { falls } / 1000 \text { patient days. } 4 \text { The } \\
\text { average monthly fall rate of } \\
5.07 \text { falls } / 1000 \text { patient days } \\
\text { for the postintervention }\end{array}$ & $\begin{array}{l}\text { Staff education and a risk stratification } \\
\text { process for bed/chair alarm use as a } \\
\text { component of an evidence-based falls } \\
\text { prevention protocol. Staff need to be well } \\
\text { aware and have a clear understanding of } \\
\text { the proper way to screen patients for falls } \\
\text { risk utilizing the organization's screening } \\
\text { tool. In addition, a uniform process for the } \\
\text { use of bed/chair alarms and a prompt } \\
\text { response to these alarms is important to } \\
\text { ensure a consistency in practice and the } \\
\text { safety of patients. } \\
\text { Ongoing falls education for staff, } \\
\text { continuing this process for bed/chair alarm } \\
\text { consistent process for the use of bed/chair } \\
\text { alarms as a component of evidence-based } \\
\text { falls prevention protocols in all inpatient } \\
\text { settings may lead to a decrease in fall } \\
\text { rates, resulting in improved patient safety. } \\
\text { The large decrease in fall rates seen during } \\
\text { this quality improvement project supports } \\
\text { the use of a consistent risk stratification }\end{array}$ \\
\hline
\end{tabular}




\begin{tabular}{|c|c|c|c|c|c|c|}
\hline & & & & $\begin{array}{l}\text { standard, } \\
\text { implementation } \\
\text { of the EBP, } \\
\text { and evaluation }\end{array}$ & $\begin{array}{l}\text { period did not decline below } \\
\text { the national average. }\end{array}$ & $\begin{array}{l}\text { process for bed/chair alarm use as a } \\
\text { component of inpatient, evidence-based } \\
\text { falls prevention programs }\end{array}$ \\
\hline $\begin{array}{l}\text { Titler et al., (2016) The effect } \\
\text { of a translating research into } \\
\text { practice intervention to } \\
\text { promote use of evidence-based } \\
\text { fall prevention interventions in } \\
\text { hospitalized adults: A } \\
\text { prospective pre-post } \\
\text { implementation study in the } \\
\text { U.S }\end{array}$ & $\begin{array}{l}\text { Randomized } \\
\text { controlled trials } \\
\text { Prospective pre- } \\
\text { post } \\
\text { implementation } \\
\text { cohort design } \\
\text { Level: I }\end{array}$ & $\begin{array}{l}\text { Sample: randomly } \\
\text { selected RN- pre- } \\
\text { intervention } 157 \\
\text { RN- post intervention } \\
140 \\
\text { Patient }>21=390 \\
\text { Setting:13 adult } \\
\text { medical surgical units' } \\
\text { selection of medical } \\
\text { records that meet the } \\
\text { inclusions (1) } \\
\text { age } \geq 21 \text { years of age, } \\
\text { (2) resided on the study } \\
\text { unit }>24 \text { hours, and ( } 3 \text { ) } \\
\text { care was received on } \\
\text { the study unit during } \\
\text { the designated data } \\
\text { abstraction period. }\end{array}$ & $\begin{array}{l}\text { Patient assessment and checklist } \\
\text { interventions } \\
\text { a set of six quick reference } \\
\text { guides to assist clinicians } \\
\text { with clinical decision- } \\
\text { making were developed and } \\
\text { organized by risk factor } \\
\text { categories with suggested fall } \\
\text { prevention interventions to } \\
\text { address each; and (2) a set of } 9 \\
\text { posters were developed about } \\
\text { falls, patient-specific fall risk } \\
\text { factors and fall prevention } \\
\text { interventions to mitigate these } \\
\text { risks. The posters were used in } \\
\text { education of staff and posted in } \\
\text { key areas on patient care units } \\
\text { such as medication rooms and } \\
\text { nurses' stations }\end{array}$ & $\begin{array}{l}\text { Rogers } \\
\text { diffusion } \\
\text { model and } \\
\text { Translation } \\
\text { research model }\end{array}$ & $\begin{array}{l}\text { Pre and Post design } \\
\text { Fall rates number of } \\
\text { inpatient falls per } 1000 \text { and } \\
\text { divide it by total number of } \\
\text { in-patient days. } \\
\text { Fall injury rates multiply by } \\
\text { number of in patient fall } \\
\text { with injuries by } 1000 \\
\text { dividing by total number of } \\
\text { in-patient days. } \\
\text { Types of Fall injuries- } \\
\text { defined as Minor"- resulted } \\
\text { in application of dressing, } \\
\text { ice or limb elevation; } \\
\text { Moderate- resulted in } \\
\text { suturing or splinting; } \\
\text { "Major"- resulted in injury } \\
\text { like traction, fracture, or } \\
\text { liver laceration and "Death"- } \\
\text { patient died as result of } \\
\text { injury caused by fall. }\end{array}$ & $\begin{array}{l}\text { The decline in fall rates from pre- } \\
\left(\mathrm{X}^{-}=3.69 ; \mathrm{SD}=1.43\right) \text { to post- } \\
\text { implementation }\left(\mathrm{X}^{-}=2.7 ; \mathrm{SD}=1.34\right) \text { was } \\
\text { not statistically significant }(-0.251 \text { on the } \\
\log \text { scale; } \mathrm{SE}=0.15) \text {, but demonstrated a } \\
\text { trend toward significance }(p=0.09) \text { with a } \\
22 \% \text { decline in fall rates. } \\
\text { Fall compliance significant improvements } \\
(p<0.001) \text { from pre- to post- } \\
\text { implementation indicating that fall } \\
\text { prevention interventions were } \\
\text { implemented to address patient-specific } \\
\text { fall risk factors } \\
\text { Number of times intervention(s) was } \\
\text { received per } 100 \text { patient days (example: } \\
\text { received a mobility intervention } 88 \text { times } \\
\text { per } 100 \text { patient days). } \\
\text { The Translating Research into Practice } \\
\text { intervention improved use of fall } \\
\text { prevention interventions targeted to } \\
\text { patient-specific fall risk factors. The study } \\
\text { also demonstrated improvement in } \\
\text { reduction of fall rates and types of fall } \\
\text { injuries. To make significant gains in } \\
\text { reducing falls in hospitals, clinicians must } \\
\text { do more than arriving at a fall risk score } \\
\text { with subsequent implementation of } \\
\text { general fall reduction interventions; they } \\
\text { need to know each patient's risk factors } \\
\text { for falls and implement fall prevention } \\
\text { interventions to mitigate those risks. }\end{array}$ \\
\hline $\begin{array}{l}\text { Tzeng and Yin Yin (2015) } \\
\text { Patient engagement in Hospital } \\
\text { Fall prevention. }\end{array}$ & $\begin{array}{l}\text { Level III } \\
\text { Garde C }\end{array}$ & N/A & $\begin{array}{l}\text { The use of selected patient } \\
\text { centric and selected clinician } \\
\text { centric assessment tool to prevent } \\
\text { falls. } \\
\text { The following patient centered } \\
\text { and clinician centered fall } \\
\text { assessment tool used AHRQ) as a } \\
\text { Universal Precautions: Morse fall } \\
\text { scale, St. Thomas Risk elderly }\end{array}$ & $\begin{array}{l}\text { Encouraged to } \\
\text { use conceptual } \\
\text { framework } \\
\text { model to guide } \\
\text { advance } \\
\text { nursing } \\
\text { leadership (The } \\
\text { conceptual } \\
\text { framework of }\end{array}$ & $\begin{array}{l}\text { Evaluating the efficacy of } \\
\text { single intervention in } \\
\text { prevention of fall in the } \\
\text { hospital is essential. } \\
\text { To conceptualize the gaps } \\
\text { the authors developed a } \\
\text { conceptual model. The } \\
\text { model was based from }\end{array}$ & $\begin{array}{l}\text { The use of selected patient centric and } \\
\text { selected clinician centric assessment tool } \\
\text { to prevent falls (. Morse fall, STRATIFY } \\
\text { Scale, Hendrick II fall, AHRQ universal } \\
\text { fall precaution, fall prevention care by } \\
\text { AHRQ, Patient and family education: } \\
\text { preventing falls in the hospital, learn not to } \\
\text { fall, fall free Spokane, Fall assessment } \\
\text { tool) }\end{array}$ \\
\hline
\end{tabular}




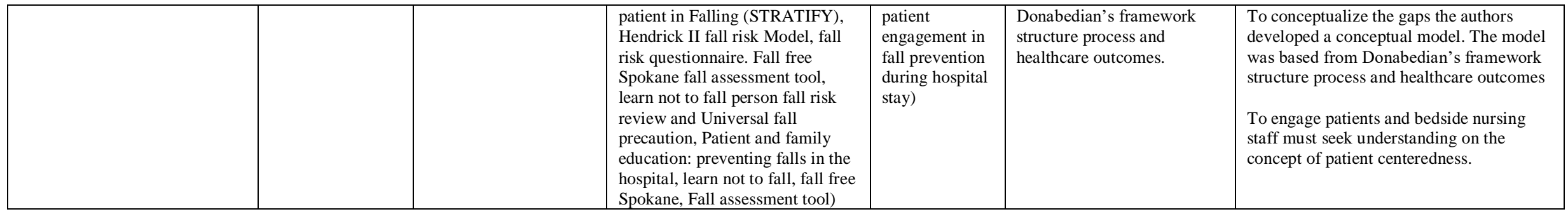

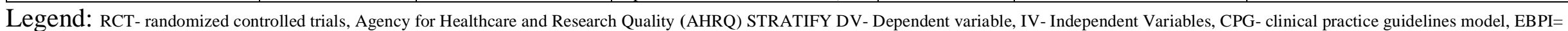
evidenced based practice improvement, CQI- continuous quality improvement 


\section{Appendix C}

Summary of Systematic Reviews (SR)

\begin{tabular}{|c|c|c|c|c|c|c|c|}
\hline Citation & $\begin{array}{l}\text { Quality } \\
\text { Grade }\end{array}$ & Question & Search Strategy & $\begin{array}{l}\text { Inclusion/ } \\
\text { Exclusion Criteria }\end{array}$ & $\begin{array}{l}\text { Data Extraction and } \\
\text { Analysis }\end{array}$ & Key Findings & $\begin{array}{l}\text { Usefulness/Recom } \\
\text { mendation/ } \\
\text { Implications }\end{array}$ \\
\hline $\begin{array}{l}\text { Ambutas et al., } \\
\text { (2017) }\end{array}$ & \begin{tabular}{|l} 
Level 1 \\
Grade A
\end{tabular} & $\begin{array}{l}\text { Does Use of specific } \\
\text { consistent fall risk } \\
\text { Assessment tool } \\
\text { decrease fall? } \\
\text { Does use of patient } \\
\text { centered fall } \\
\text { Checklist or toolkit } \\
\text { reduce fall? } \\
\\
\text { Does use of } \\
\text { consistent fall } \\
\text { prevention and } \\
\text { patient - family and } \\
\text { nurse engagement } \\
\text { reduce fall? }\end{array}$ & $\begin{array}{l}\text { CINAHL, PubMed, } \\
\text { ProQuest }\end{array}$ & $\begin{array}{l}\text { The inclusion criteria applied were } \\
\text { systematic review, randomized } \\
\text { controlled trials, qualitative study, } \\
\text { quasi experimental patients, } \\
\text { hospitals, adult, healthcare } \\
\text { hospitals. The exclusion criteria } \\
\text { applied were: non-English } \\
\text { language, non-intervention, } \\
\text { commentaries, community } \\
\text { dwellings, psychiatric, pediatrics, } \\
\text { psychogeriatric, and hospice } \\
\text { setting. }\end{array}$ & $\begin{array}{l}\text { The use of AHRQ fall } \\
\text { toolkit. } \\
\text { Unit based champions. } \\
\text { Establishing } \\
\text { interprofessional } \\
\text { individualized care plan }\end{array}$ & $\begin{array}{l}\text { Reduce falls with injury to less } \\
\text { than } 0.3 \text { per } 1,000 \text { patient days } \\
\text { on study units. } \\
\text { Reduce falls without injury on } \\
\text { study units to less than } 3.4 \text { per } \\
1,000 \text { patient days. }\end{array}$ & \begin{tabular}{|l} 
AHRQ toolkit include \\
fall risk assessment has \\
been used and prevented \\
falls \\
The need for \\
individualizing the care \\
plan and use of checklist \\
can guide nurse in the \\
fall prevention \\
implementation. \\
\\
Staff were involved in \\
problem analysis, fall \\
toolkit implementation, \\
ongoing review of falls, \\
and continual evaluation \\
of the process. The \\
organization's safety \\
climate improved as staff \\
became accountable for \\
reducing falls and \\
preventing injury.
\end{tabular} \\
\hline $\begin{array}{l}\text { Ayton et } \\
\text { al,(2017) }\end{array}$ & $\begin{array}{l}\text { Level } 1 \\
\text { Grade A }\end{array}$ & $\begin{array}{l}\text { Does Use of specific } \\
\text { consistent fall risk } \\
\text { Assessment tool } \\
\text { decrease fall? } \\
\text { Does use of patient } \\
\text { centered fall } \\
\text { Checklist or toolkit } \\
\text { reduce fall? } \\
\text { Does use of } \\
\text { consistent fall } \\
\text { prevention and } \\
\text { patient - family and } \\
\text { nurse engagement } \\
\text { reduce fall? }\end{array}$ & $\begin{array}{l}\text { CINAHL, PubMed, } \\
\text { ProQuest }\end{array}$ & $\begin{array}{l}\text { The inclusion criteria applied were } \\
\text { systematic review, randomized } \\
\text { controlled trials, qualitative study, } \\
\text { quasi experimental patients, } \\
\text { hospitals, adult, healthcare } \\
\text { hospitals. The exclusion criteria } \\
\text { applied were: non-English } \\
\text { language, non-intervention, } \\
\text { commentaries, community } \\
\text { dwellings, psychiatric, pediatrics, } \\
\text { psychogeriatric, and hospice } \\
\text { setting. }\end{array}$ & $\begin{array}{l}\text { Nurse Survey } \\
42 \text { item nurse survey was } \\
\text { developed to assess beliefs } \\
\text { about falls; current fall } \\
\text { prevention practices. } 6 \\
\text { PACK program } \\
\text { components, best practices } \\
\text { guidelines key } \\
\text { recommendations; and } \\
\text { reporting practices were } \\
\text { included. }\end{array}$ & \begin{tabular}{|l}
702 surveys- 420 returned $60 \%$ \\
Barriers: old beliefs that fall \\
are inevitable, lack of \\
resources, lack of ownership \\
and complacency \\
Enabler: Training and \\
education, use of fall data, \\
feedback on progress, engage \\
staff in fall prevention \\
Barrier identified: beliefs that \\
fall cannot be prevented, \\
imited knowledge on fall \\
prevention, and lack of \\
ownership.
\end{tabular} & $\begin{array}{l}\text { 6 PACK is a nurse driven } \\
\text { checklist interventions. } \\
\text { It include assessment. } \\
\text { checklist and } \\
\text { intervention. } \\
\text { There was no patient } \\
\text { education mentioned or } \\
\text { engagement. } \\
\text { Champions were } \\
\text { identified and reported as } \\
\text { an important } \\
\text { implementation strategy. }\end{array}$ \\
\hline
\end{tabular}




\begin{tabular}{|c|c|c|c|c|c|c|c|}
\hline & & & & & & \begin{tabular}{|l} 
Enablers: education and \\
training, improved leadership, \\
use of data to drive practice \\
change, use of reminders, \\
audits and feedback. The need \\
to have leaders and champions. \\
Strategies to a successful 6 \\
pack program: \\
Face to face education, \\
leadership champion, \\
compliance audit, reminders \\
and feedback
\end{tabular} & \\
\hline $\begin{array}{l}\text { Cuesta } \\
\text { Benjumea et } \\
\text { al., (2017) }\end{array}$ & \begin{tabular}{|l} 
Level III \\
Quality B
\end{tabular} & $\begin{array}{l}\text { Does Use of specific } \\
\text { consistent fall risk } \\
\text { Assessment tool } \\
\text { decrease fall? } \\
\text { Does use of patient } \\
\text { centered fall } \\
\text { Checklist or toolkit } \\
\text { reduce fall? } \\
\text { Does use of } \\
\text { consistent fall } \\
\text { prevention and } \\
\text { patient - family and } \\
\text { nurse engagement } \\
\text { reduce fall? }\end{array}$ & $\begin{array}{l}\text { CINAHL, PubMed, } \\
\text { ProQuest }\end{array}$ & $\begin{array}{l}\text { The inclusion criteria applied were } \\
\text { systematic review, randomized } \\
\text { controlled trials, qualitative study, } \\
\text { quasi experimental patients, } \\
\text { hospitals, adult, healthcare } \\
\text { hospitals. The exclusion criteria } \\
\text { applied were: non-English } \\
\text { language, non-intervention, } \\
\text { commentaries, community } \\
\text { dwellings, psychiatric, pediatrics, } \\
\text { psychogeriatric, and hospice } \\
\text { setting. }\end{array}$ & $\begin{array}{l}\text { The use of standardized } \\
\text { tool (JBI- MAStARI) }\end{array}$ & $\begin{array}{l}\text { Analyze and synthesize } \\
\text { qualitative and quantitative } \\
\text { studies } \\
\text { Synthesize description of } \\
\text { intervention and roles played } \\
\text { by care providers. }\end{array}$ & 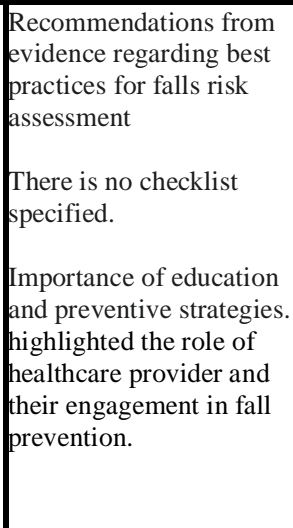 \\
\hline $\begin{array}{l}\text { Dykes et } \\
\text { al.,(2017) }\end{array}$ & $\begin{array}{l}\text { Level I } \\
\text { Grade A }\end{array}$ & $\begin{array}{l}\text { Does Use of specific } \\
\text { consistent fall risk } \\
\text { Assessment tool } \\
\text { decrease fall? } \\
\text { Does use of patient } \\
\text { centered fall } \\
\text { Checklist or toolkit } \\
\text { reduce fall? } \\
\text { Does use of } \\
\text { consistent fall } \\
\text { prevention and } \\
\text { patient - family and } \\
\text { nurse engagement } \\
\text { reduce fall? }\end{array}$ & $\begin{array}{l}\text { CINAHL, PubMed, } \\
\text { ProQuest }\end{array}$ & $\begin{array}{l}\text { The inclusion criteria applied were } \\
\text { systematic review, randomized } \\
\text { controlled trials, qualitative study, } \\
\text { quasi experimental patients, } \\
\text { hospitals, adult, healthcare } \\
\text { hospitals. The exclusion criteria } \\
\text { applied were: non-English } \\
\text { language, non-intervention, } \\
\text { commentaries, community } \\
\text { dwellings, psychiatric, pediatrics, } \\
\text { psychogeriatric, and hospice } \\
\text { setting. }\end{array}$ & 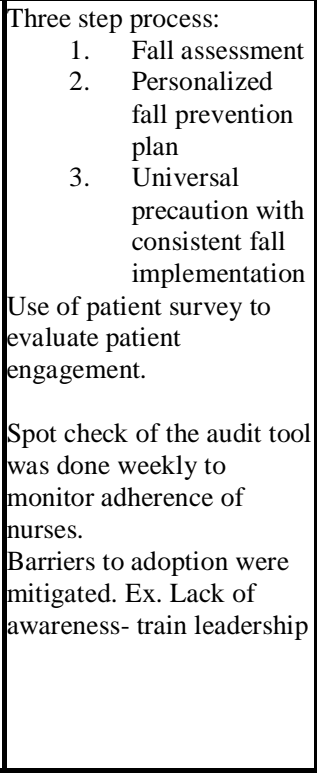 & \begin{tabular}{|l|} 
The use of of IHI framework \\
for spread provide a \\
infrastructure to support \\
communication and adoption. \\
And ultimately decrease falls. \\
Results: BWH hospital More \\
than 80 percent Adherence to \\
the toolkit. Mean fall rate \\
decreased from $3.28-2.80$ per \\
1000 patient days Jan to June \\
2015 versus 2016 \\
MMC hospital toolkit \\
compliance averaged to $91 \%$ \\
mean fall injury rate decreased \\
from 0.47 to 0.31 per 1000 \\
patient days
\end{tabular} & $\begin{array}{l}\text { Performing fall risk } \\
\text { assessment (Morse Fall). } \\
\text { Staff need to be involved } \\
\text { in the process of tailoring } \\
\text { and implementing the } \\
\text { toolkit and redesigning } \\
\text { the workflow to engage } \\
\text { patients and family in the } \\
\text { 3-step fall prevention } \\
\text { process. The } \\
\text { interventions can be } \\
\text { modified based on } \\
\text { organizational policy and } \\
\text { patient needs. } \\
\text { Patient engagement and } \\
\text { nurse consistent } \\
\text { intervention in the fall } \\
\text { checklist poster and EHR } \\
\text { Leadership support to } \\
\text { sustain fall. } \\
\text { Framework will maintain } \\
\text { toolkit adoption, sustain }\end{array}$ \\
\hline
\end{tabular}




\begin{tabular}{|c|c|c|c|c|c|c|c|}
\hline & & & & & & & $\begin{array}{l}\text { evidence fall prevention } \\
\text { and prevent falls } \\
\text { The use of a framework } \\
\text { to address barriers is a } \\
\text { framework for } \\
\text { improvement }\end{array}$ \\
\hline $\begin{array}{l}\text { Johnston and } \\
\text { Magnon (2019 }\end{array}$ & $\begin{array}{l}\text { Level II } \\
\text { Grade C }\end{array}$ & $\begin{array}{l}\text { Does Use of specific } \\
\text { consistent fall risk } \\
\text { Assessment tool } \\
\text { decrease fall? } \\
\text { Does use of patient } \\
\text { centered fall } \\
\text { Checklist or toolkit } \\
\text { reduce fall? } \\
\text { Does use of } \\
\text { consistent fall } \\
\text { prevention and } \\
\text { patient - family and } \\
\text { nurse engagement } \\
\text { reduce fall? }\end{array}$ & $\begin{array}{l}\text { CINAHL, PubMed, } \\
\text { ProQuest }\end{array}$ & $\begin{array}{l}\text { The inclusion criteria applied were } \\
\text { systematic review, randomized } \\
\text { controlled trials, qualitative study, } \\
\text { quasi experimental patients, } \\
\text { hospitals, adult, healthcare } \\
\text { hospitals. The exclusion criteria } \\
\text { applied were: non-English } \\
\text { language, non-intervention, } \\
\text { commentaries, community } \\
\text { dwellings, psychiatric, pediatrics, } \\
\text { psychogeriatric, and hospice } \\
\text { setting. }\end{array}$ & $\begin{array}{l}\text { The use of fall checklist as } \\
\text { a handoff report. Most } \\
\text { common errors on the } 14 \\
\text { items fall checklist } \\
\text { interventions are: } \\
\text { Bed alarm, signage }\end{array}$ & $\begin{array}{l}\text { No fall occurred during pilot } \\
\text { program. } \\
\text { A sharp decline in the fall } \\
\text { incidence } \\
\text { Small number of observation } \\
\text { and short period of time. } \\
\text { monthly fall rate of } 3.6 \\
\text { falls/1000 patient days and a } \\
44.5 \% \text { decrease in the actual } \\
\text { number of falls per month. } \\
\text { The pilot unit had an average } \\
\text { monthly fall rate during the } \\
\text { pre-intervention period of } 8.67 \\
\text { falls/1000 patient days, }\end{array}$ & $\begin{array}{l}\text { Performing Schmidt fall } \\
\text { risk assessment tool } \\
\text { Using fall checklist can } \\
\text { promote adherence of the } \\
\text { fall interventions. } \\
\text { Checklist map out } \\
\text { minimum steps } \\
\text { necessary to completely } \\
\text { and correctly do the } \\
\text { multiple task. Checklist } \\
\text { will prevent oversight. } \\
\text { There was no patient } \\
\text { education done or patient } \\
\text { engagement. Education } \\
\text { training and nurse } \\
\text { adherence was measured } \\
\text { through a checklist } \\
\text { evaluation }\end{array}$ \\
\hline Melin, (2018) & \begin{tabular}{|l} 
Level I \\
Grade A
\end{tabular} & $\begin{array}{l}\text { Does Use of specific } \\
\text { consistent fall risk } \\
\text { Assessment tool } \\
\text { decrease fall? } \\
\text { Does use of patient } \\
\text { centered fall } \\
\text { Checklist or toolkit } \\
\text { reduce fall? } \\
\text { Does use of } \\
\text { consistent fall } \\
\text { prevention and } \\
\text { patient - family and } \\
\text { interprofessional } \\
\text { engagement reduce } \\
\text { fall? }\end{array}$ & $\begin{array}{l}\text { CINAHL, PubMed, } \\
\text { ProQuest }\end{array}$ & $\begin{array}{l}\text { The inclusion criteria applied were } \\
\text { systematic review, randomized } \\
\text { controlled trials, qualitative study, } \\
\text { quasi experimental patients, } \\
\text { hospitals, adult, healthcare } \\
\text { hospitals. The exclusion criteria } \\
\text { applied were: non-English } \\
\text { language, non-intervention, } \\
\text { commentaries, community } \\
\text { dwellings, psychiatric, pediatrics, } \\
\text { psychogeriatric, and hospice } \\
\text { setting. }\end{array}$ & & $\begin{array}{l}\text { The pre-intervention period of } \\
8.67 \text { falls } / 1000 \text { patient days. } \\
\text { The average monthly fall rate } \\
\text { of } 5.07 \text { falls } / 1000 \text { patient days }\end{array}$ & \begin{tabular}{|l|} 
Consistent Fall risk \\
stratification using \\
Morse fall risk \\
>45 score are on High \\
fall risk and bed alarm \\
and chair alarm are \\
activated \\
Automatic intervention \\
of Universal fall \\
precaution. There was no \\
checklist used but \\
intervention is patient \\
centered. \\
Staff received training \\
and education and was \\
done prior to \\
implementation. Patient \\
education was not \\
mentioned.
\end{tabular} \\
\hline
\end{tabular}




\begin{tabular}{|c|c|c|c|c|c|c|c|}
\hline & & & & & & & $\begin{array}{l}\text { Education and consistent } \\
\text { risk stratification reduced } \\
\text { falls. Ongoing falls } \\
\text { education for staff }\end{array}$ \\
\hline $\begin{array}{l}\text { Titler et al., } \\
(2016)\end{array}$ & $\begin{array}{l}\text { Level I } \\
\text { Grade A }\end{array}$ & $\begin{array}{l}\text { Does Use of specific } \\
\text { consistent fall risk } \\
\text { Assessment tool } \\
\text { decrease fall? } \\
\text { Does use of patient } \\
\text { centered fall } \\
\text { Checklist or toolkit } \\
\text { reduce fall? } \\
\text { Does use of } \\
\text { consistent fall } \\
\text { prevention and } \\
\text { patient - family and } \\
\text { nurse engagement } \\
\text { reduce fall? }\end{array}$ & $\begin{array}{l}\text { CINAHL, PubMed, } \\
\text { ProQuest }\end{array}$ & $\begin{array}{l}\text { The inclusion criteria applied were } \\
\text { systematic review, randomized } \\
\text { controlled trials, qualitative study, } \\
\text { quasi experimental patients, } \\
\text { hospitals, adult, healthcare } \\
\text { hospitals. The exclusion criteria } \\
\text { applied were: non-English } \\
\text { language, non-intervention, } \\
\text { commentaries, community } \\
\text { dwellings, psychiatric, pediatrics, } \\
\text { psychogeriatric, and hospice } \\
\text { setting. }\end{array}$ & $\begin{array}{l}\text { Translating research into } \\
\text { Practice to implement the } \\
\text { targeted risk factor fall } \\
\text { prevention bundle. }\end{array}$ & $\begin{array}{l}\text { Impact on falls } \\
\text { Demonstrated a decrease trend } \\
\text { with } 22 \% \text { decline in fall. } \\
\text { Decline in fall injury was not } \\
\text { significant. } \\
\text { Adoption of fall bundle } \\
\text { showed significant } \\
\text { improvement. }\end{array}$ & \begin{tabular}{|l} 
Fall risk assessment \\
Patient centered checklist \\
interventions. \\
a set of six quick \\
reference guides to assist \\
clinicians with clinical \\
decision-making were \\
developed and organized \\
by risk factor categories \\
with suggested fall \\
prevention interventions \\
to address. \\
Consistent strategies on \\
fall. Leadership \\
involvement, staff \\
education, change champ \\
ions using in services.
\end{tabular} \\
\hline
\end{tabular}

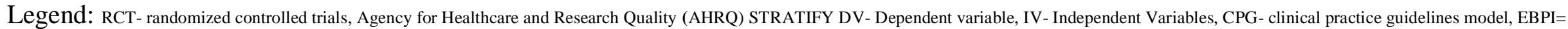
evidenced based practice improvement, CQI- continuous quality improvement 


\section{Appendix D}

The IOWA Model of Evidence-Based Practice

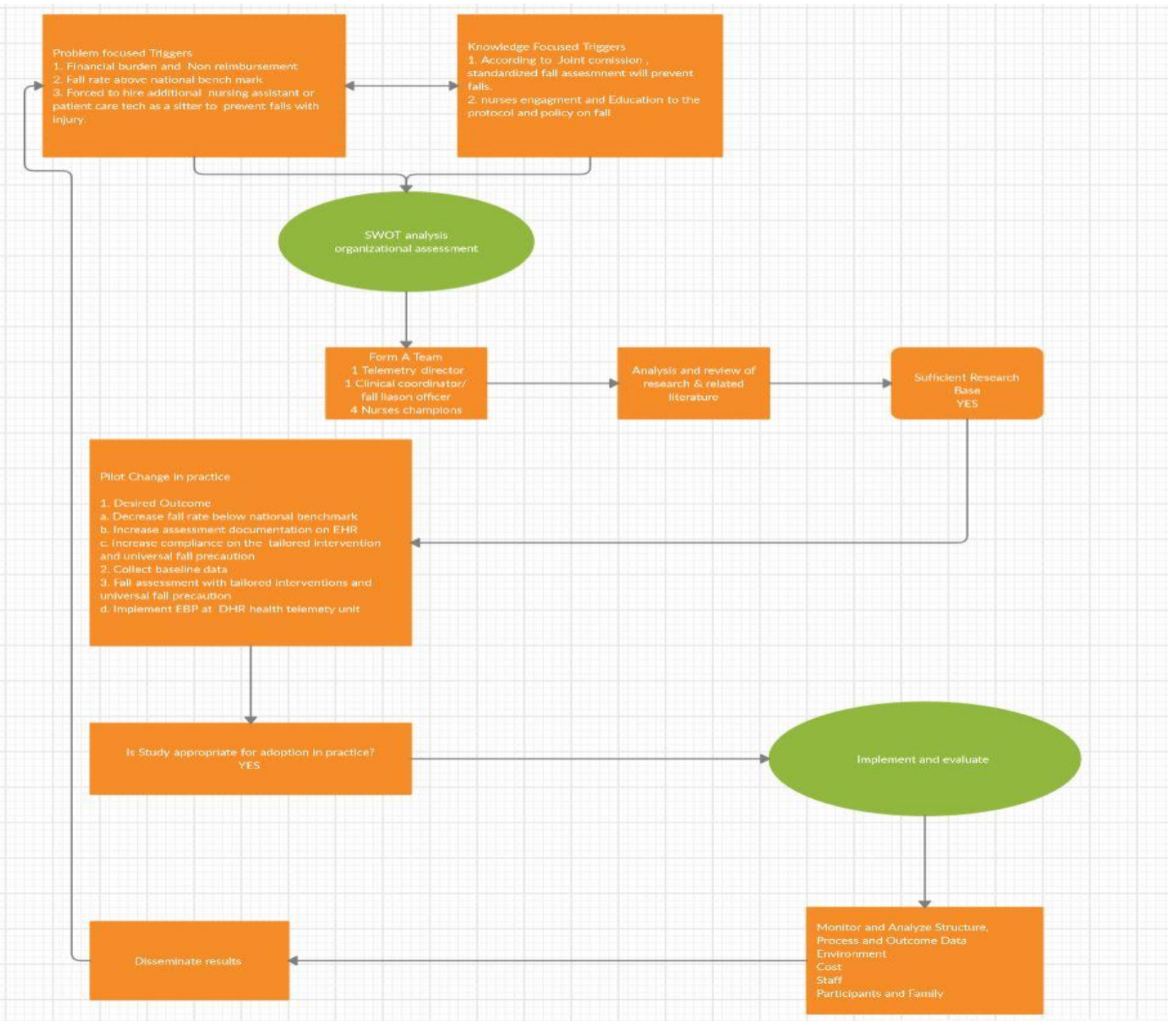

Adapted from "The Iowa model of evidence-based practice to promote quality care." by Titler et al., 2001, Critical Care Nursing Clinics of North America, 13(4), 497-509. Copyright 1998 by University of Iowa Hospitals and Clinics. 


\section{Appendix E}

\section{USAHS Approval}

University of St. Augustine for Health Sciences

Doctor of Nursing Practice Program

Evidence-Based P ractice Review Council

1 University Blvd.

St. Augustine, FL 32086

February 13, 2020

Dear Roda S. Galang,

Your proposal titled The use of tailored intervention to prevent falls: A quality improvement project in the telemetry unit has been reviewed by the University of St. Augustine for Health Sciences Doctor of Nursing Practice Evidence-Based Practice Review Council (EPRC) and determined to:

meet the requirements for research as defined in the Federal Register. You must make adjustments to the proposal to reflect the DNP program requirements and resubmit for additional review. Work closely with your faculty member during this process.

_. not meet the requirements for research as defined in the Federal Register. Your proposal reflects an evidence-based p ractice change project. The proposal must be implemented as submitted (changes are not permitted). You may proceed to obtain approvals from the facility where the project will be implemented. Implementation may not beg in until you are not ified in writing by faculty that you may implement the project.

Questions regarding the USAHS approval process should be addressed to Dr. Douglas Turner at DTurnen@usa.edu. Questions regarding the facility approval process should be addressed to course faculty.

Sincerely,

\section{Douglas Turner}

Douglas M Turner, PhD, DNP, RN, CNE, NE-BC, NEA-BC 


\section{Appendix F}

\section{DHR IRB Approval}
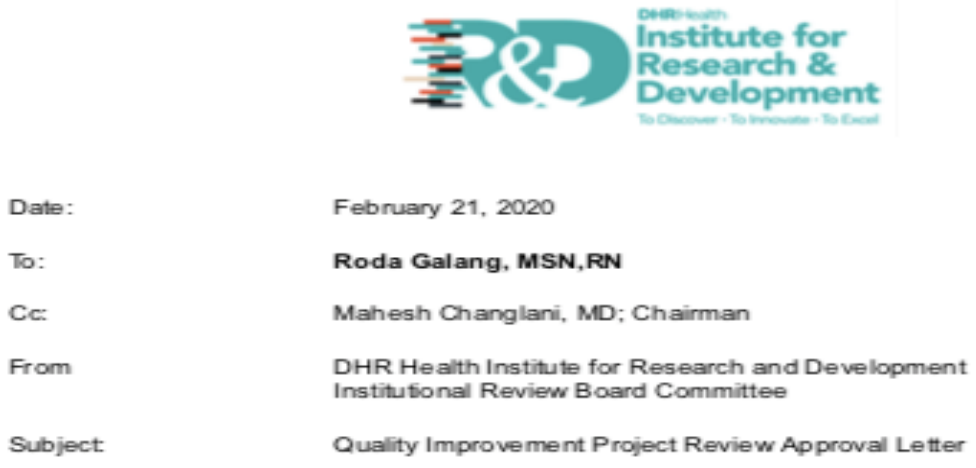

Study Closeout Report: This study does not have an expiration date. However, you are required to submit a study closeout report at the completion of the project

Sincer elly.

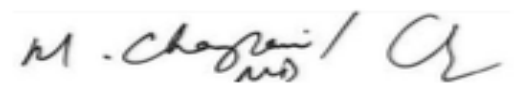

Mahesh Changlani, MD

Chairman

DHR Health Institute for Research and Development

Institutional Review Board 


\section{Appendix G}

\section{Organization Letter of Support}

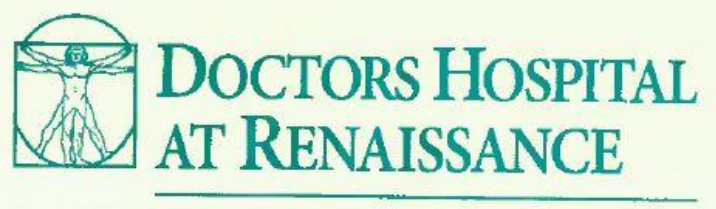

HEALTH SYSTEM

January 29,2020

RE: QI Project on Fall Prevention

Dear IRB Committee Members.

We, at the nursing department, are excited to work with DNP Student, Roda S. Galang MSN, RN and are supportive of her quality improvement project to help us prevent falls. We already have a falls prevention program in place; however, we have seen a rise in patient falls across the hospital -particularly in our PCCU. She is helping us put in place an evidence-based tailored intervention for falls as a quality improvement project. There is strong evidence from the past decades that tailored fall prevention programs are effective (Fall T.I.P.S. nd). The proposed intervention includes universal fall precautions and a three-step fall prevention process (fall risk assessment, tailored fall prevention care planning, consistent implementation of the tailored care plan and post fall management plan).

Please do not hesitate to reach out with any questions.

Respectfully submitted.

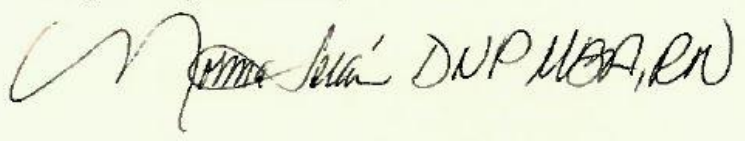

Norma Teran DNP MBA, RN

Executive VP - Chief Nursing Officer

956-362-7155 office

956-342-0197 cell 


\section{Appendix H}

\section{Letter to use Poster Tailored intervention}

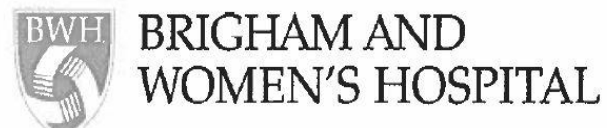

\section{HARVARD MEDICAL SCHOOL}

$1 / 9 / 2020$

To Whom it May Concern,

This message grants St. Augustine University permission to implement Fall TIPS (Tailoring Intervention for Patient Safety) within their domains. This is an evidence-based tool that has been developed, tested, and validated over the past decade at Brigham and Women's Hospital and other collaborating hospitals. Given that the Fall TIPS tool is our property, we ask that you do not alter the tool without written permission from us. You may add your logo, but please send us the final version of the poster for approval.

Sincerely,

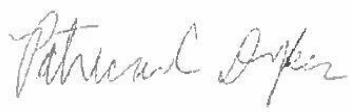

Patricia C. Dykes, PhD, RN, FAAN, FACMI

Program Director Research

Center for Patient Safety, Research, and Practice

Brigham and Women's Hospital

Associate Professor of Medicine

Harvard Medical School

Office: 617-525-6654 | Mobile: 617-850-5748

pdykes@bwh.harvard.edu 


\section{Appendix I}

\section{SWOT Analysis}

\section{STRENGTH}

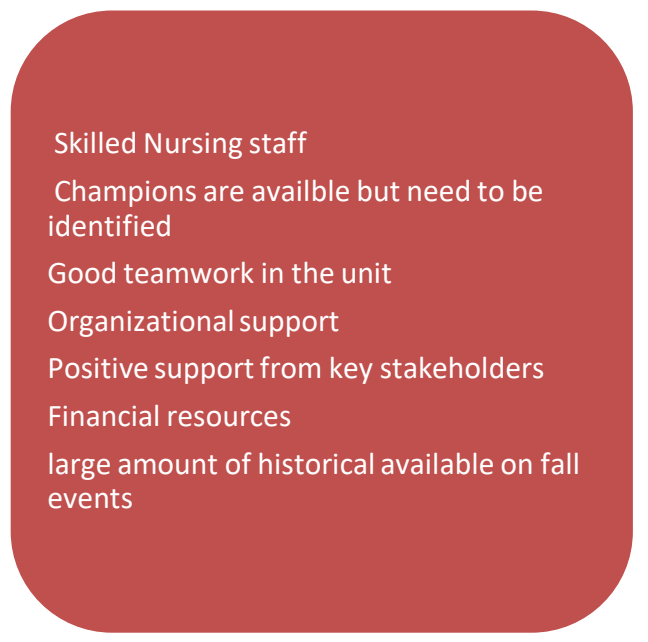

\section{Opportunities}

Increase Revenue

Improve Knowledge and Skills through training and education

Increase in HCAHPS score

Reduction of sitter utilization

Reduce Fall

Decrease cost of care to family

Increase reimbursement

Improve Quality of care

Increase in HCAHPS lack of familiarity on the project

lack of feed back

Lack of ownwership

Some staff are resistance to change

lack of consistent policy and lack of innovation to EBP fall prevention

poor knowledge regarding protocol

knowledge and attitude of some

stakeholder regarding new guideline

Lack of reinforcment on the project cultural acclimation by staff to the old policy and guidelines.

Lack of motivation to engae in the new policy.

Staff may percieve that involving patient, families in the fall prevention can risk patient safety.

\section{Weakness}

\section{Threats}




\section{Appendix J}

\section{Project Gannt Chart}

\begin{tabular}{|c|c|c|c|c|}
\hline PROJECT TITLF-The use of Fall checklist intery & vention-A a & éc & vement & \\
\hline & & & & \\
\hline TASK NAME & STAFT DATE & DUE DATE & DUPATION & \\
\hline TASK: Project planning and implementation & $10+15+2019$ & $8+3012020$ & 320 & \\
\hline Building the DNP Project Proposal & $9+15+2019$ & $12+20+2019$ & 75 & \\
\hline Drganizational Assessment & $10+1+2019$ & $11+15+2019$ & 14 & \\
\hline Project approwal ('W'ritten and Dral Presentatoion) & 1012012019 & $12+20+2015$ & 60 & \\
\hline Fall toolkit supplies and educational materials & $12+12019$ & $12120+2019$ & 20 & \\
\hline Meet with atskeholders for proposol and project presentation & $1+15+2020$ & $1+3012020$ & 15 & \\
\hline DHFI IRE and USAHS submission and approval & $1+23+2020$ & $2+2812020$ & 36 & \\
\hline Chief Medical Officer and Chief Wursing Officer Approval of the project & $01+15+20$ & $01130+20$ & 15 & \\
\hline Conduct Gop Analysis prior to implementation & $01+15+20$ & 02102120 & 18 & \\
\hline $\begin{array}{l}\text { Presentation of the STOP Foll in the telemetry and recruit unit } \\
\text { participation }\end{array}$ & 12 ro1?19 & $01+20120$ & 50 & \\
\hline Present policy and STOP fall initiative Program & $01+15+20$ & $01+15+20$ & O & \\
\hline Finalise data collection. ealculate and validate & $01+15+20$ & $02+20120$ & 36 & \\
\hline $\begin{array}{l}\text { Policy and standardiestion of the sitter utiliestion protocol and safety } \\
\text { squipments. }\end{array}$ & $11+15+2019$ & $2+15+2020$ & 92 & Presel \\
\hline Present product eafety evaluation to value anslysis council & $1+15+2019$ & $10+31+2019$ & 289 & \\
\hline Presentation of the final STOP Foll quality improvement to stokeholder & $1+15+2020$ & $01+15+20$ & O & \\
\hline $\begin{array}{l}\text { Presentation of the gosl and objectives of the quality improvement } \\
\text { project to the Key gtakeholders }\end{array}$ & $2+15+2020$ & $2+15+2020$ & $\mathbf{O}$ & \\
\hline Collsborstion with HER ( Informatics) & $11130+2019$ & $1+5+2020$ & 36 & \\
\hline Telemetry educational training & $2+10+2020$ & $3+5+2020$ & 24 & \\
\hline Final check of policy. protocol on sitter utilisation & $2+1+2020$ & $2+15+2020$ & 14 & \\
\hline Implimentation of the STOP fall quality improvement Project ( GO LIVE) & $3+15+2020$ & $3+15+2020$ & O & \\
\hline Supervise and onsite avaislability of the YM rendor & $3+15+2020$ & 413012020 & 46 & \\
\hline Huddle for evalustion and feed back & $3+15+2020$ & $4 \sqrt{2012020}$ & 36 & \\
\hline Daily monitoring for 1 week & $3+15+2020$ & $3+2212020$ & 7 & \\
\hline PDSA cycle improvement effort & $3+15+2020$ & $5+5+2020$ & 51 & \\
\hline Transition to weckly mecting with Staff Champions & $4+2012020$ & $5+10+2020$ & 20 & \\
\hline Transition to Bi weekly meeting with stoff champions & $5+10+2020$ & $6+10+2020$ & 31 & \\
\hline Assese proiect, evoluate and revised sechedule if needed & $6+15+2020$ & $7+15+2020$ & 30 & \\
\hline Collect dats and evalauste if need extension on evalustion & $4+3012020$ & $5+5 r 2020$ & 5 & \\
\hline Qusliky improvement project end date & $5+10+2020$ & $5+10+2020$ & $\mathbf{O}$ & \\
\hline Dats calculation with atatistician & $6+20+2020$ & $7+10+2020$ & 20 & \\
\hline Finslize outcome meseure dats & $7+10+2020$ & $7+3012020$ & 20 & \\
\hline Project report & $12+10+2019$ & $12 \sqrt{20}+2019$ & 10 & \\
\hline Submizsion of Project Report & $6+2012020$ & $8+1+2020$ & 40 & \\
\hline Presentation of the resulte to the etakeholdere and key lesders & 713012020 & 713012020 & $\mathrm{O}$ & \\
\hline DWP Project wite ups & $8+1+2020$ & $8+512020$ & 4 & \\
\hline DWP Project final revision & $8+15+2020$ & $8+15+2020$ & $\mathrm{O}$ & \\
\hline Presentation of the DNPP proiect results & 813012019 & 813012019 & & \\
\hline & & & & \\
\hline
\end{tabular}




\section{Appendix K}

\section{Cost Analysis}

\begin{tabular}{|l|l|l|l|}
\hline Items & Cost & Evaluation Quantity & $\begin{array}{l}\text { Cost } \\
\text { Assumptions }\end{array}$ \\
\hline $\begin{array}{l}\text { Proposed cost of Fall initiative } \\
\text { Program }\end{array}$ & $\$ 23,136$ & Total cost & $13,397.70$ \\
\hline RN Staff Training (100 RN) & $\$ 35 / h r$. & $\begin{array}{l}\text { 2 hour/ FTE, 48 RN per unit x } \\
2 \text { telemetry }\end{array}$ & $\$ 6720$ \\
\hline $\begin{array}{l}\text { Patient Safety Supplies } \\
\text { chair alarm, clip alarms) }\end{array}$ & $\$ 3000$ & Institutional budget support & $\$ 3000$ \\
\hline $\begin{array}{l}\text { Monthly staff meeting to } \\
\text { celebrate Fall initiative } \\
\text { Success }\end{array}$ & $\$ 0$ & 3 monthly meeting 2 floor & 0 \\
\hline Fall materials & $\$ 1500$ & 2 telemetry units & $\$ 3000$ \\
\hline $\begin{array}{l}\text { Patient Centered TIPS } \\
\text { Posters (64 rooms) }\end{array}$ & $\$ 127.20$ & 64 rooms & $\$ 127.70$ \\
\hline $\begin{array}{l}\text { Falling star signage on the } \\
\text { ceiling }\end{array}$ & 550 & Pamphlet / Posters & $\$ 550$ \\
\hline Educational Materials & 0 & 0 & Total expenses \\
\hline & & Proposed total budget & $\$ 13,339.7$ \\
& & Proposed training for nurses & 6720 \\
\hline & & & $0,6777=$ Total \\
\hline
\end{tabular}


Appendix L

Educational One to One Training Using the Poster

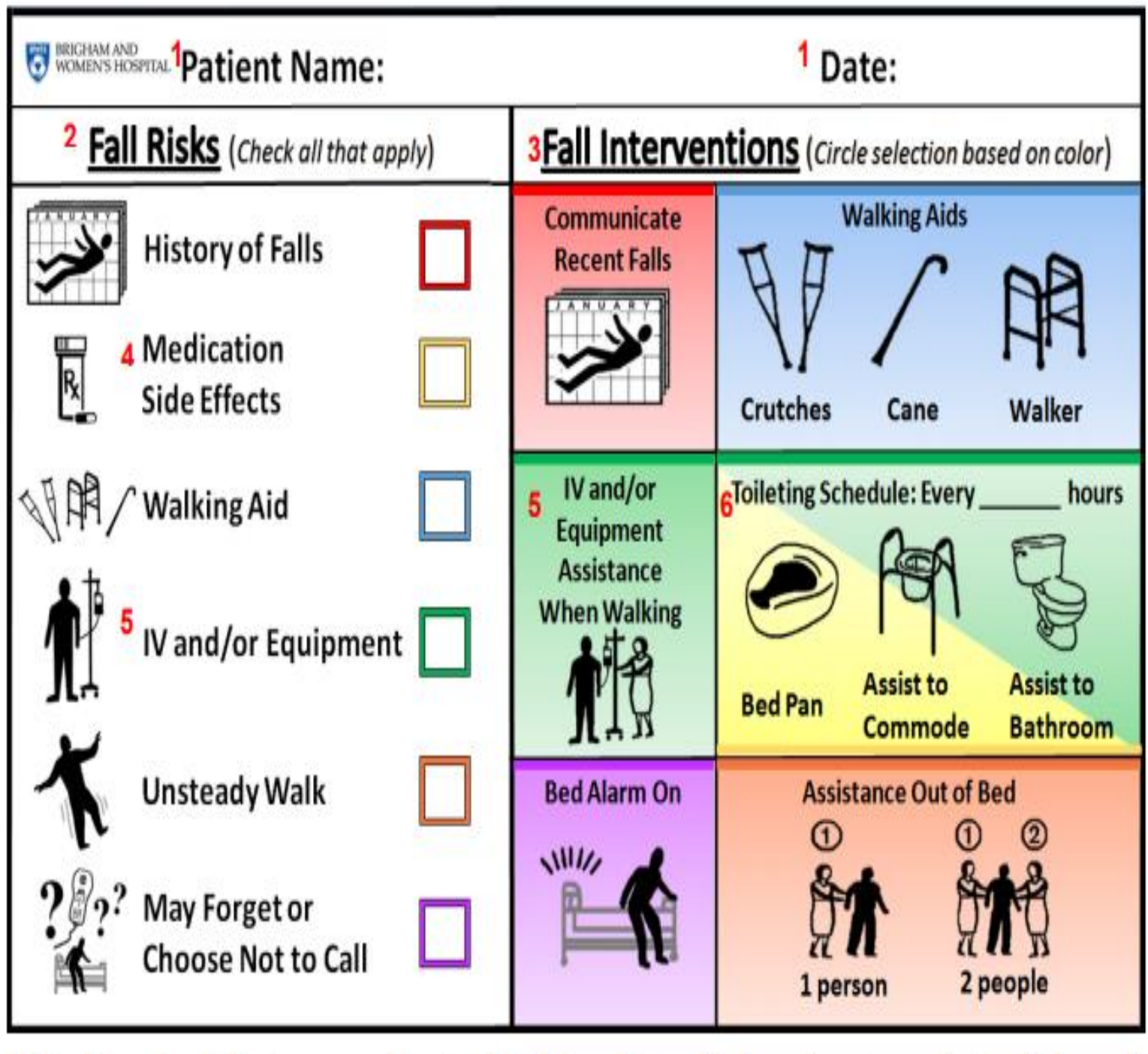

Dykes, P.C., et al., Fall prevention in acute care hospitals: a randomized trial. JAMA, 2010. 304(17): p. 1912-8. 


Increased Risk
of Harm If You Fall

Adapted from Dykes, P.C., et al., Fall prevention in acute care hospitals: a randomized trial. JAMA, 2010. 304(17): p. 1912-8. 


\section{FALL PREVENTION}

\section{ASK YOUR NURSE ABOUT YOUR PERSONALIZED FALL PREVENTION PLAN}

On admission, your nurse will meet with you to assess your risk for falling while you are in the hospital. The nurse and your care team will use this assessment to create a personalized fall prevention plan to keep you safe in the hospital.

Once the nurse enters your responses into your electronic health record, he/she can circle your personal fall risks and fall interventions on the colored Fall TIPS poster. This poster will be placed at your bedside to communicate your individual risks for falling and the interventions to prevent you from falling. It will be updated throughout your stay at the hospital.

Why is fall prevention important?

Being in the hospital increases your risk of falling:

- $3 \%$ of hospitalized patients fall

- $30 \%$ of these falls results in injury

Falling at the hospital could delay the course of your treatment and prolong the length of your stay at the hospital.

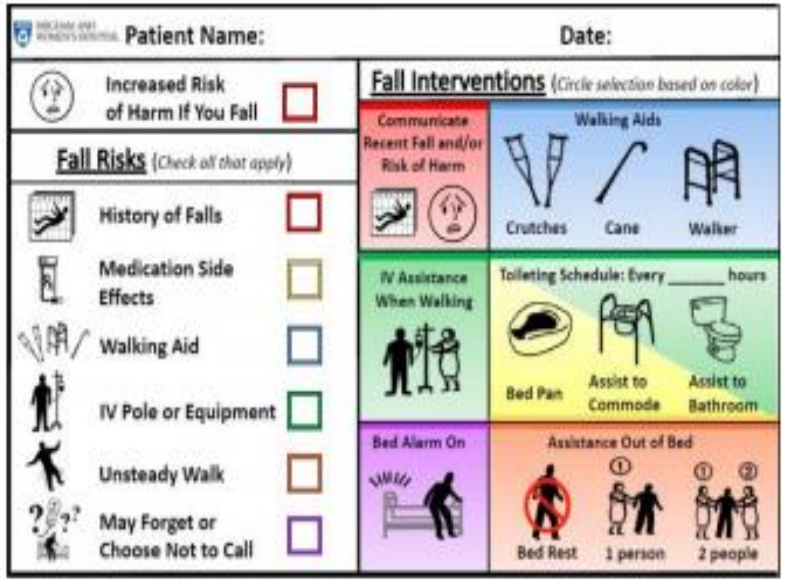

Ask your nurse about your fall risk factors and personalized fall prevention plan so we can work together to keep you safe.

Adapted from Dykes, P.C., et al., Fall prevention in acute care hospitals: a randomized trial. JAMA, 2010. 304(17): p. 1912-8 


\section{Appendix M}

\section{Electronic Health Record PowerPoint training}
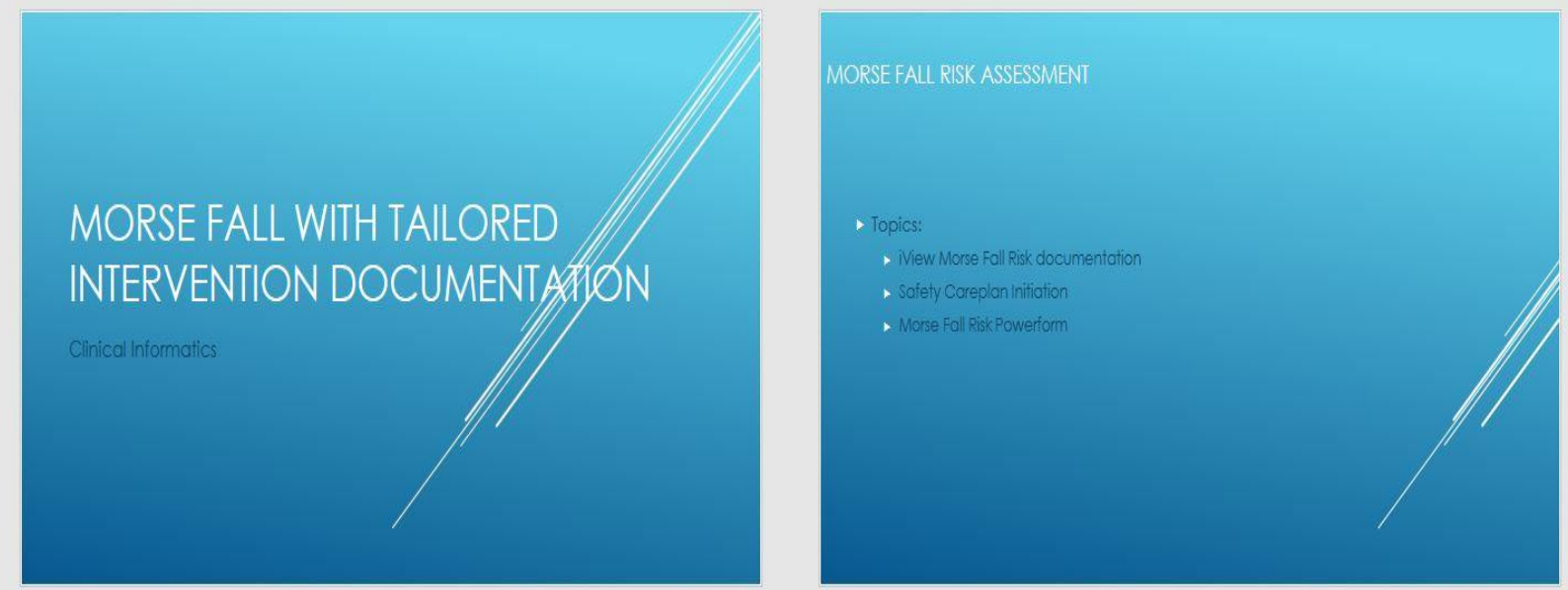

1

2
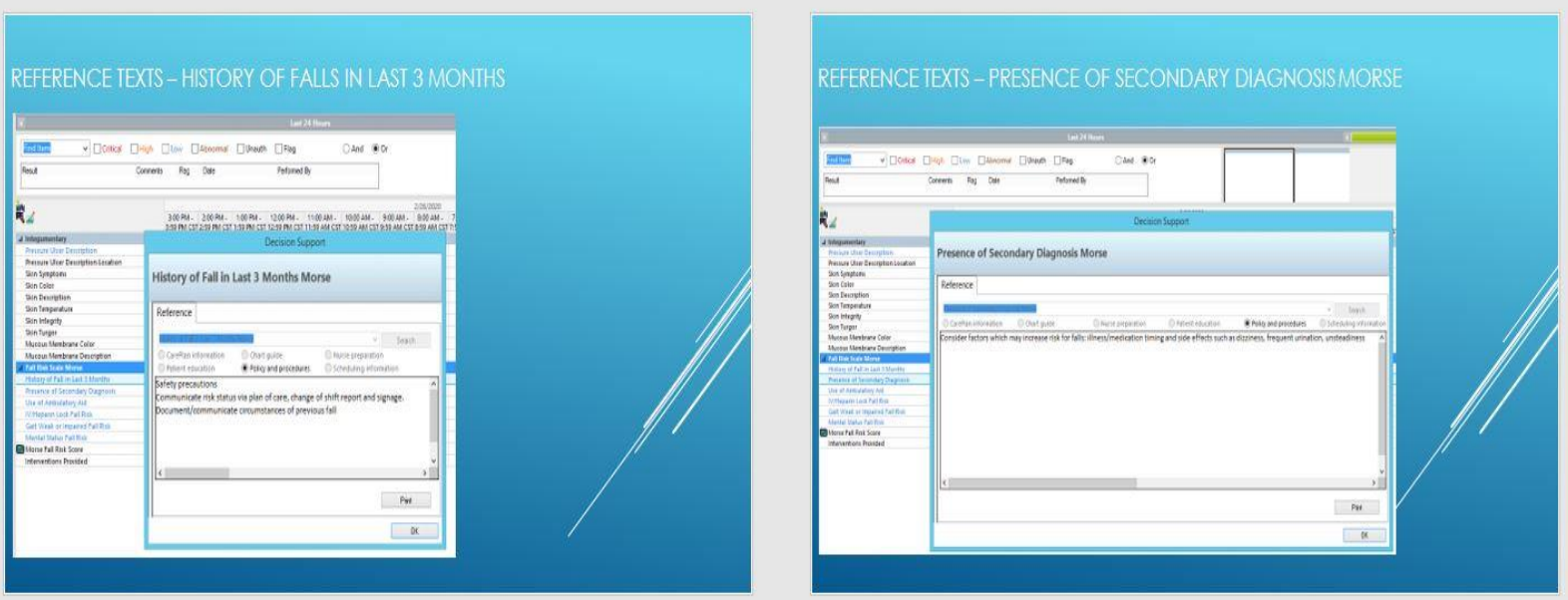

3

4 


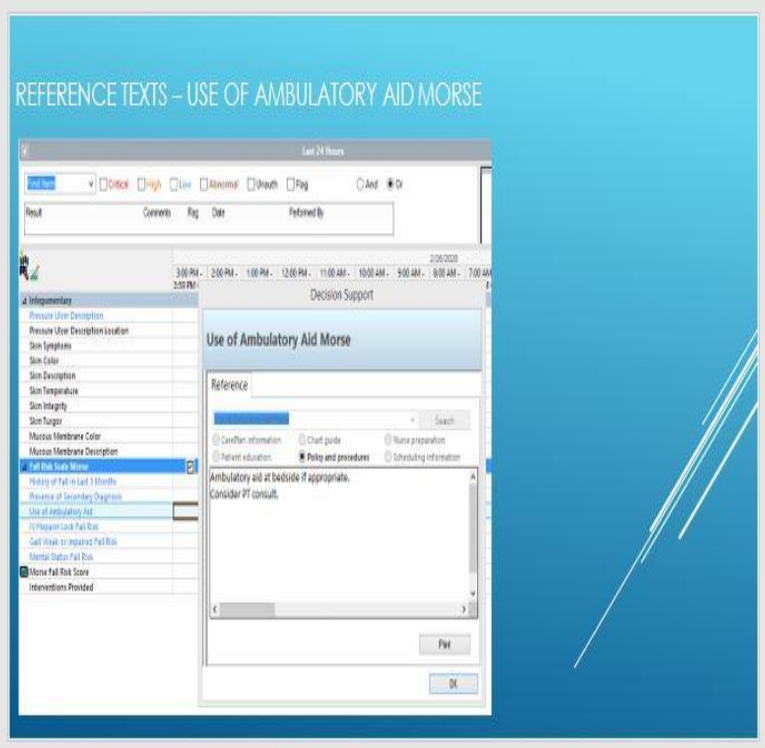

5

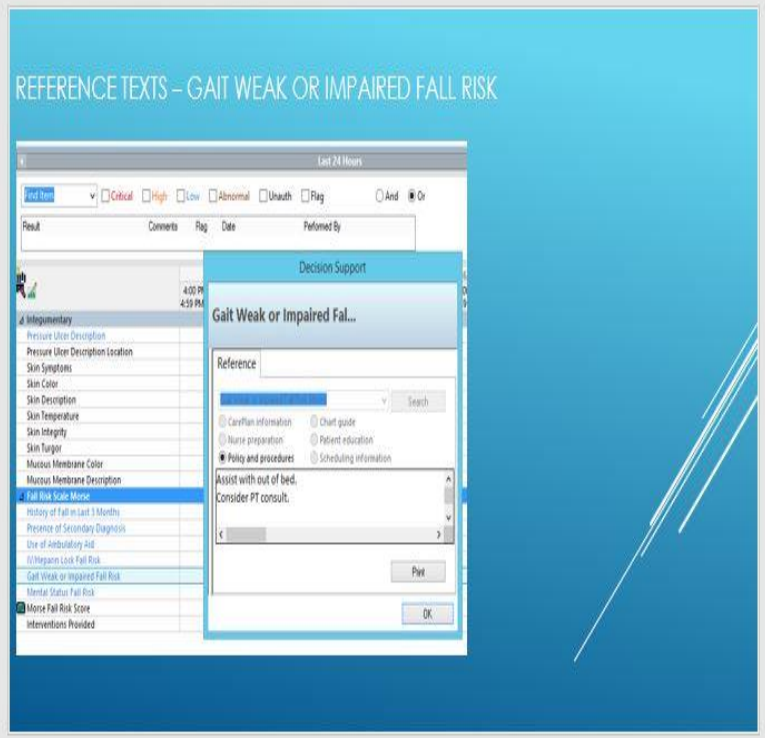

7
REFERENCE TEXIS - IVIHEPARIN LOCK FALL RISKMORSE

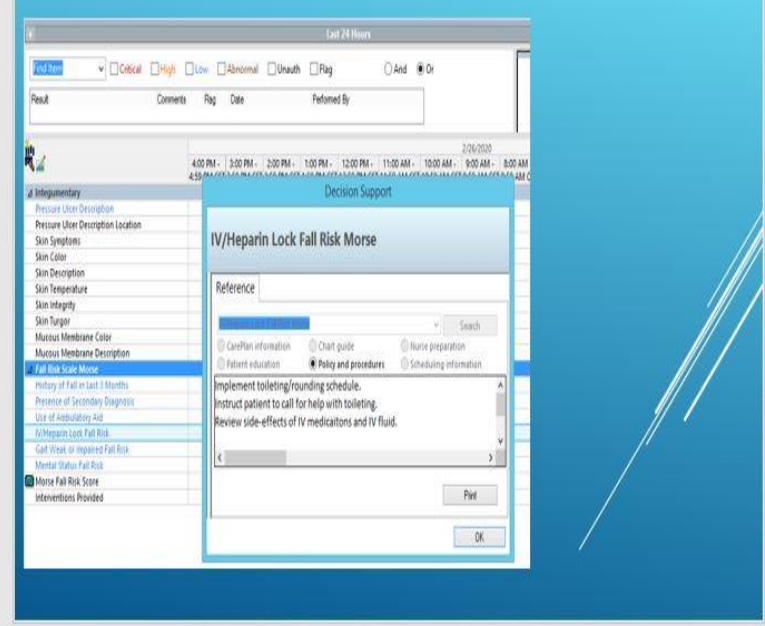

6

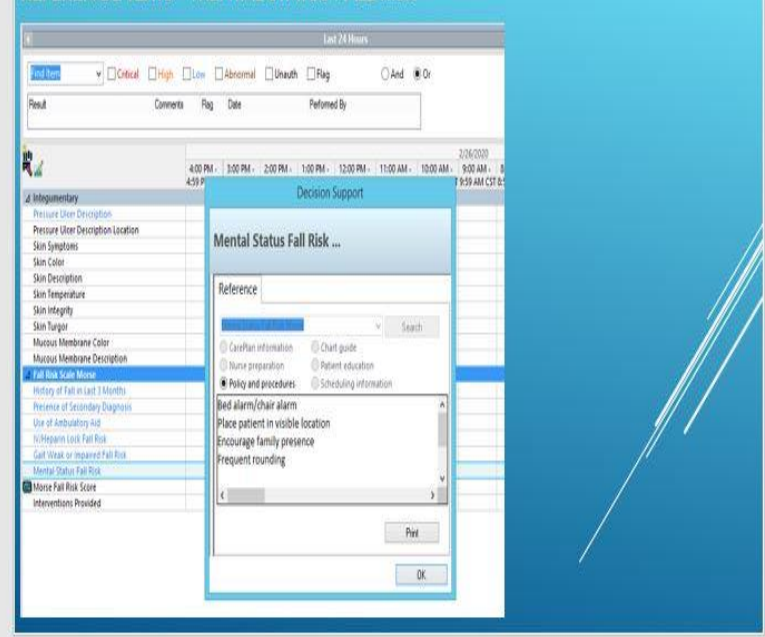




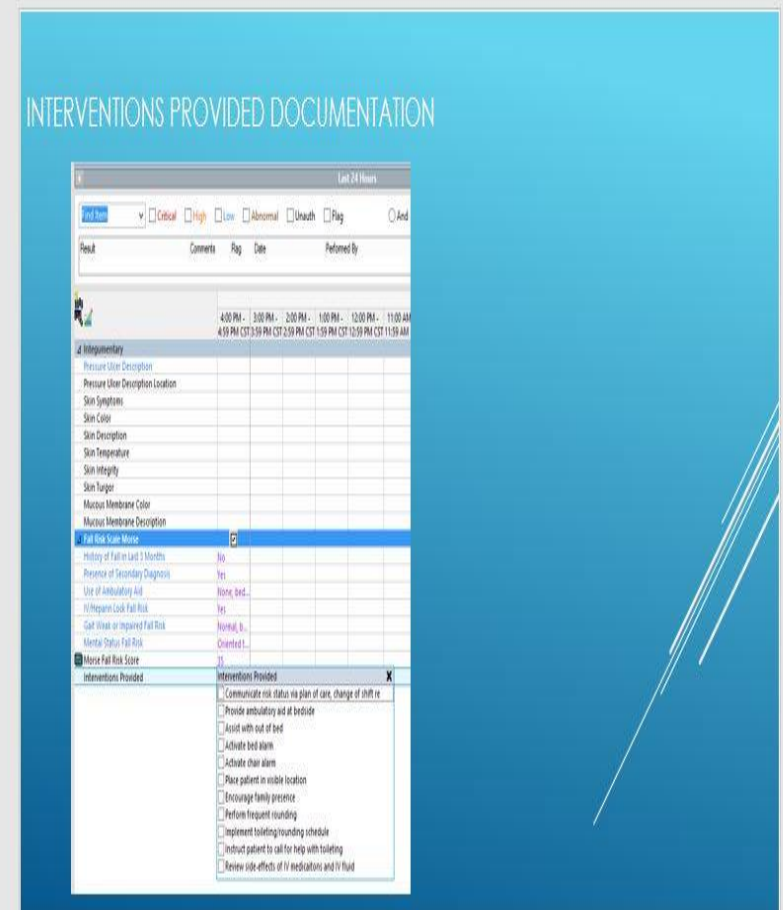

9

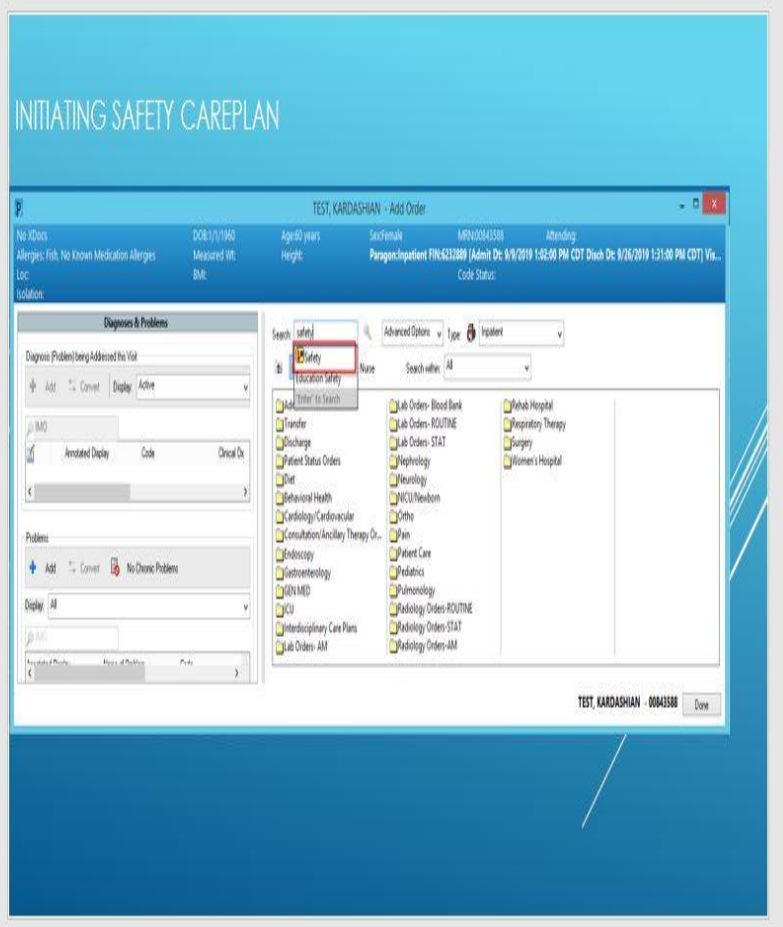

10

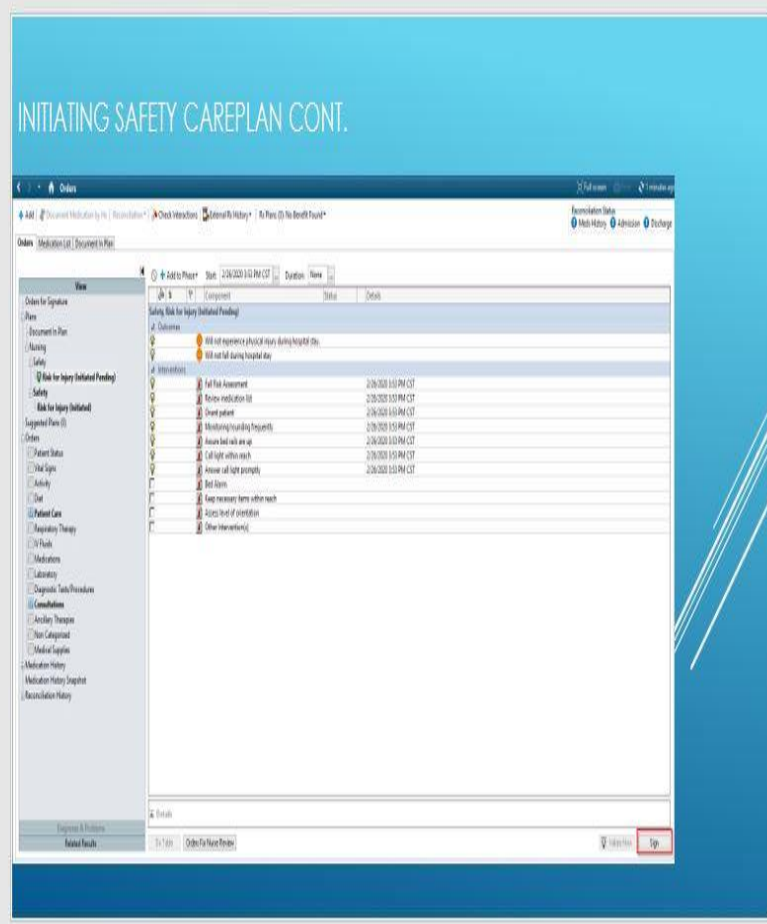

12 


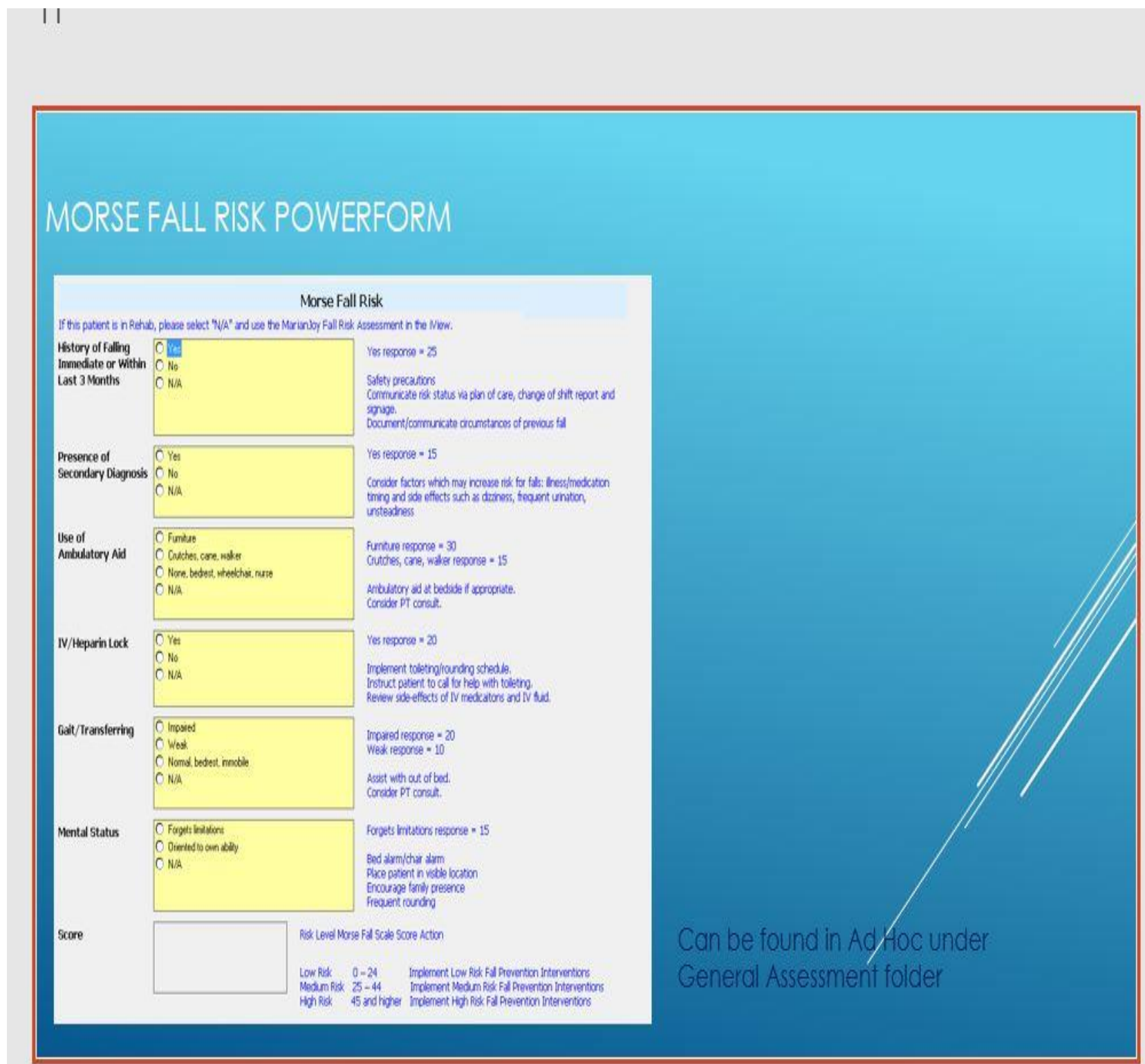

13 


\section{Appendix N}

\section{Metrics}

\begin{tabular}{|c|c|}
\hline Measures & Results \\
\hline Sustainability Measures & $\begin{array}{l}\text { Percentage of engagement of the members on falls team }(>90 \%) \\
\text { Percentage completion of fall huddle and yearly training }(>90) \\
\text { Percentage of professional RN to participate in the Fall Initiative ( }> \\
90 \% \text { Nurse Champions) }\end{array}$ \\
\hline Process Measures & $\begin{array}{l}\text { Percentage Fall risk assessment/ reassessment (Number of patients } \\
\text { identified as high, moderate, low risk to fall) }(>90 \%) \\
\text { Percentage Fall prevention interventions (e.g. no slip socks, assistive } \\
\text { devices, handrails, low bed, chair and bed exit alarms) (>90\%) } \\
\text { More than } 75 \% \text { compliance in the Fall injury prevention } \\
\text { interventions } \\
\text { More than } 75 \% \text { Adherence in the Completion of the Morse fall } \\
\text { assessment Checklist with interventions } \\
\text { More than } 75 \% \text { adherence on Post fall assessment }\end{array}$ \\
\hline Outcome Measures & $\begin{array}{l}\text { More than } 75 \% \text { Nurses' adherence on the Fall checklist } \\
\text { More than } 50 \% \text { reduction in fall rate per } 1000 \text { patient days } \\
\text { More than } 50 \% \text { reduction in Fall injury rate per } 1000 \text { patient days } \\
\text { More than } 80 \% \text { patient engagement in their plan intervention } \\
\text { Reduction in fall rate below national bench mark of } 3.44 / 1000 \\
\text { patient days }\end{array}$ \\
\hline Financial Measures & $\begin{array}{l}\text { Total Cost of falls with injury in the telemetry per year } \\
\text { Total cost of supllies for fall prevention } \\
\text { Total Cost of training and other educational materials }\end{array}$ \\
\hline Balancing Measures & $\begin{array}{l}\text { Number of sitters used as an alternative to the fall prevention } \\
\text { intervention } \\
\text { Percentage in the use of restraints to prevent patient from getting } \\
\text { out of bed and falling } \\
\text { Percent of Staff injury (associated with assisted fall) }\end{array}$ \\
\hline
\end{tabular}

\section{Appendix 0}




\section{DHR Health Baseline Fall Rate 2018-2019}

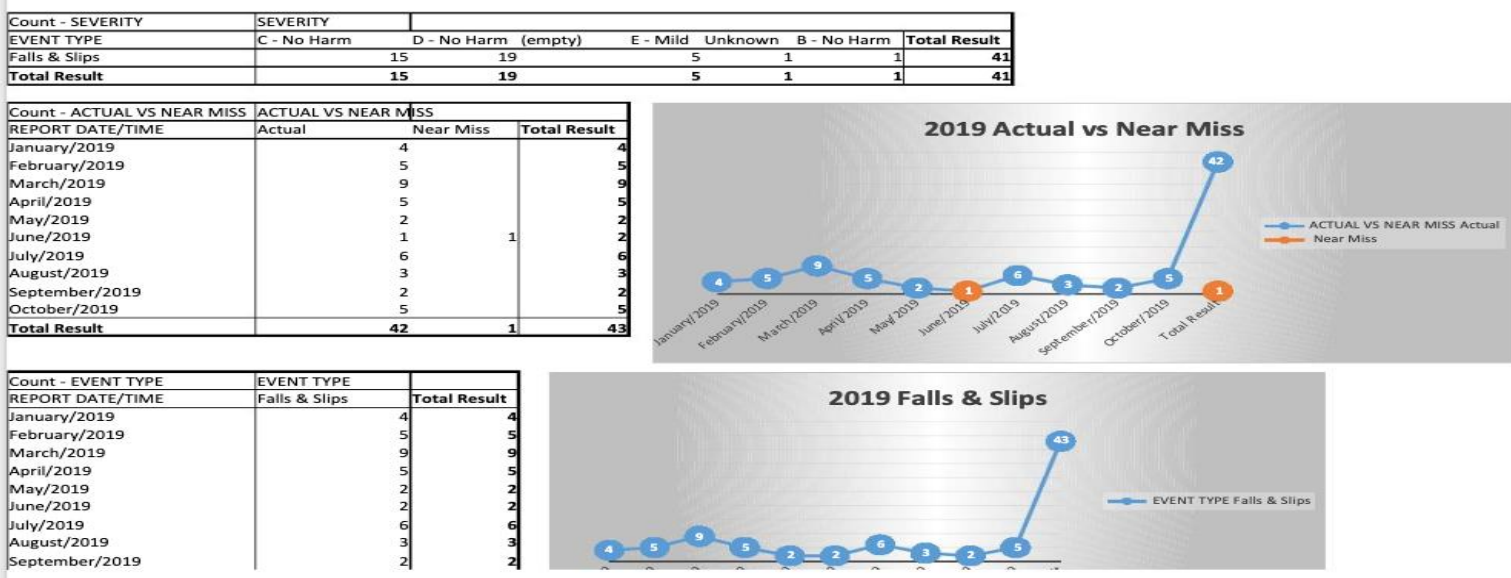

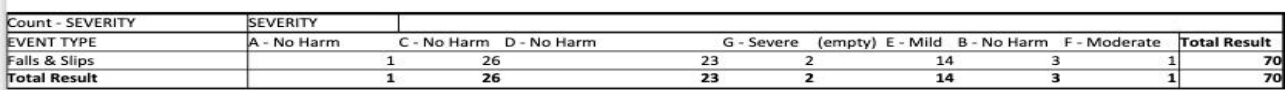

\begin{tabular}{|c|c|c|c|c|}
\hline REPORT DATE/TIME & Actual & Near Miss & Total Result & \\
\hline January/2018 & & & & \\
\hline February/2018 & & & & \\
\hline March/2018 & 1 & & & \\
\hline April//2018 & & & & \\
\hline May/2018 & & & & \\
\hline June/2018 & & & & \\
\hline July/2018 & & & 1 & \\
\hline August $/ 2018$ & & & 2 & \\
\hline September/2018 & & 3 & 1 & \\
\hline October/2018 & & & 1 & \\
\hline November $/ 2018$ & & 4 & 1 & \\
\hline December/2018 & & & & \\
\hline
\end{tabular}

2018 Actual vs Near Miss

Total Result

Count - EVENT TYP

lanuary/2018

February/201

March/2018

May/2018

June/2018

July/2018

August $/ 2018$

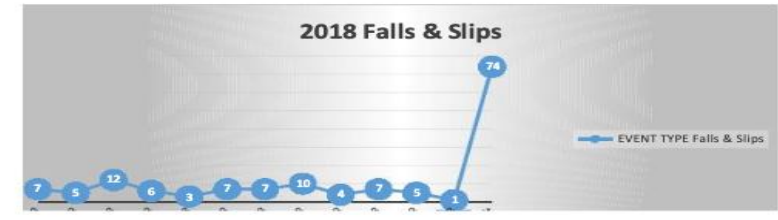

actual vS near miss actua

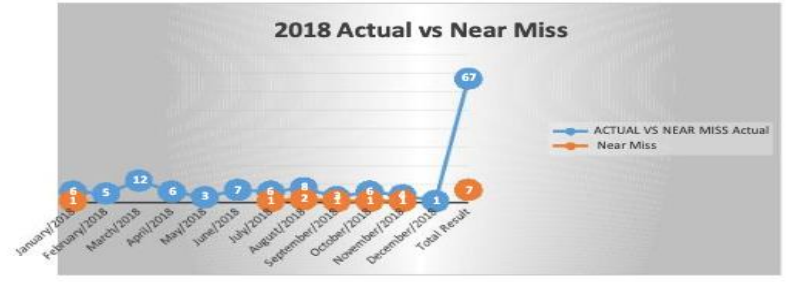

(

\begin{tabular}{|r|r|}
\hline 7 & Total Result \\
5 & 7 \\
12 & 5 \\
6 & 12 \\
3 & 6 \\
7 & 3 \\
7 & 7 \\
10 & 7 \\
4 & 10 \\
\hline
\end{tabular}

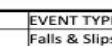

Falls \& Slips




\section{Appendix P}

\section{DHR Fall Audit Tool}

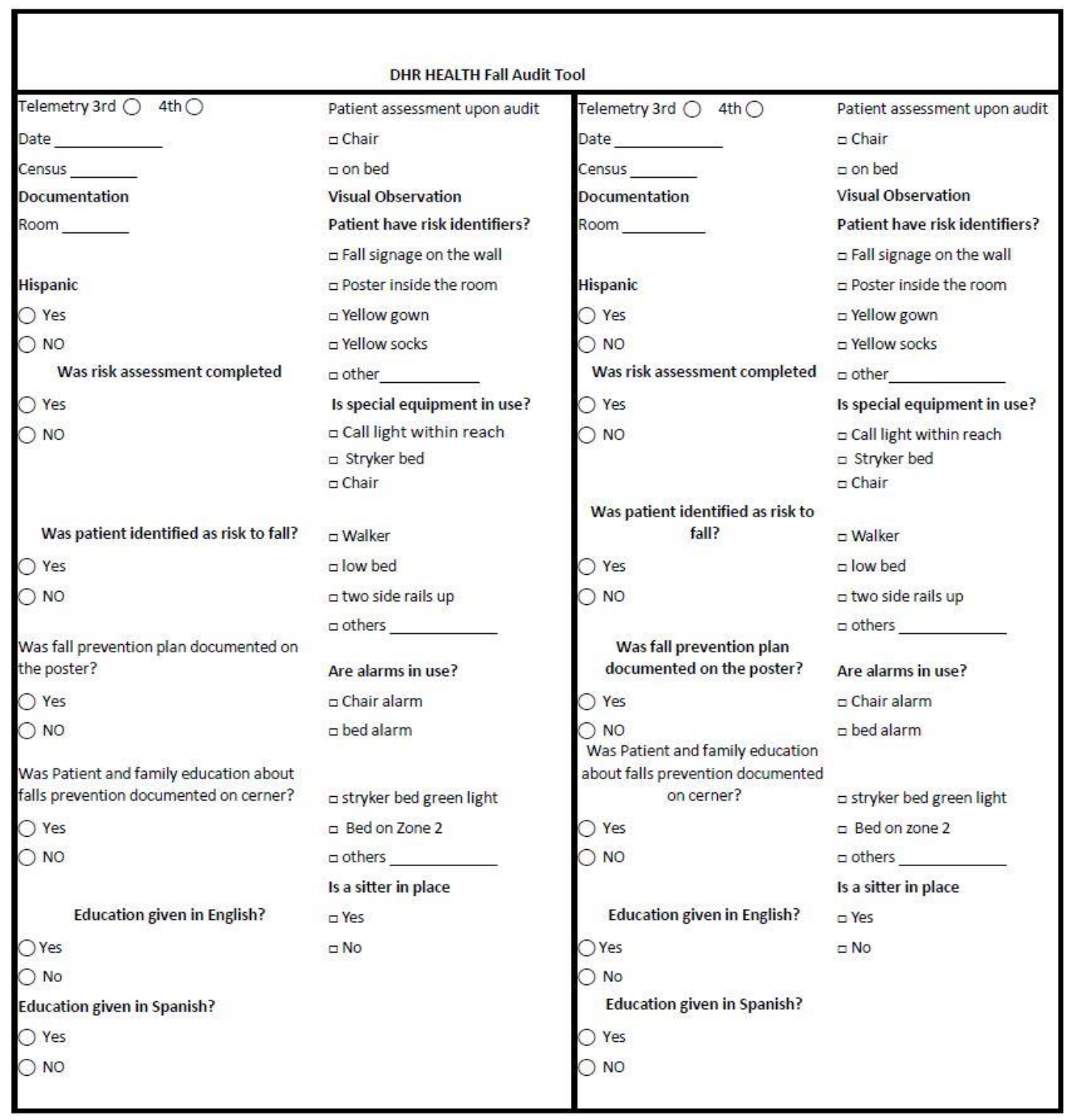

Adapted from the Pennsylvania Patient Safety Fall Audit Tool (PSA. nd) 


\section{Appendix Q}

\section{Audit Result Distribution}
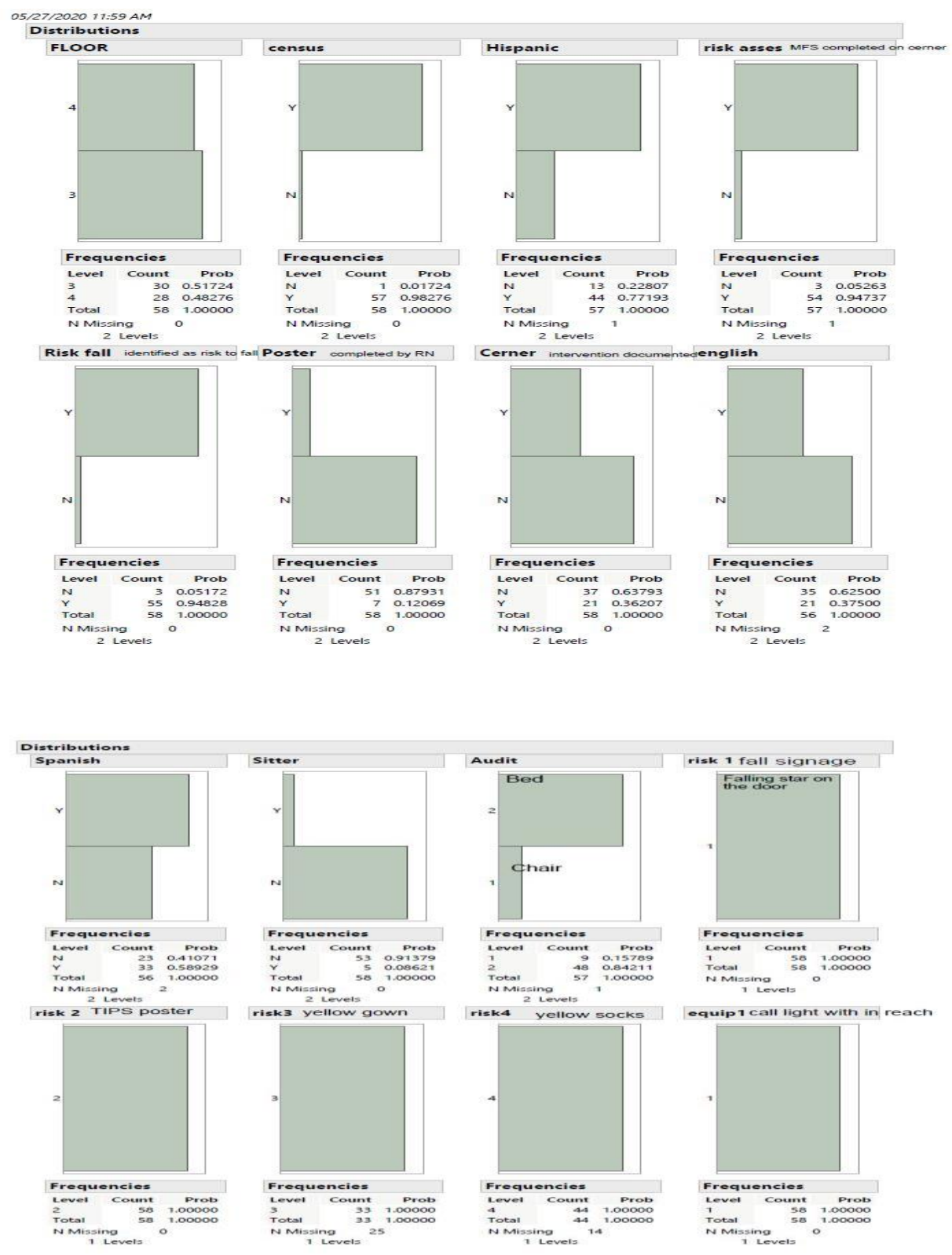

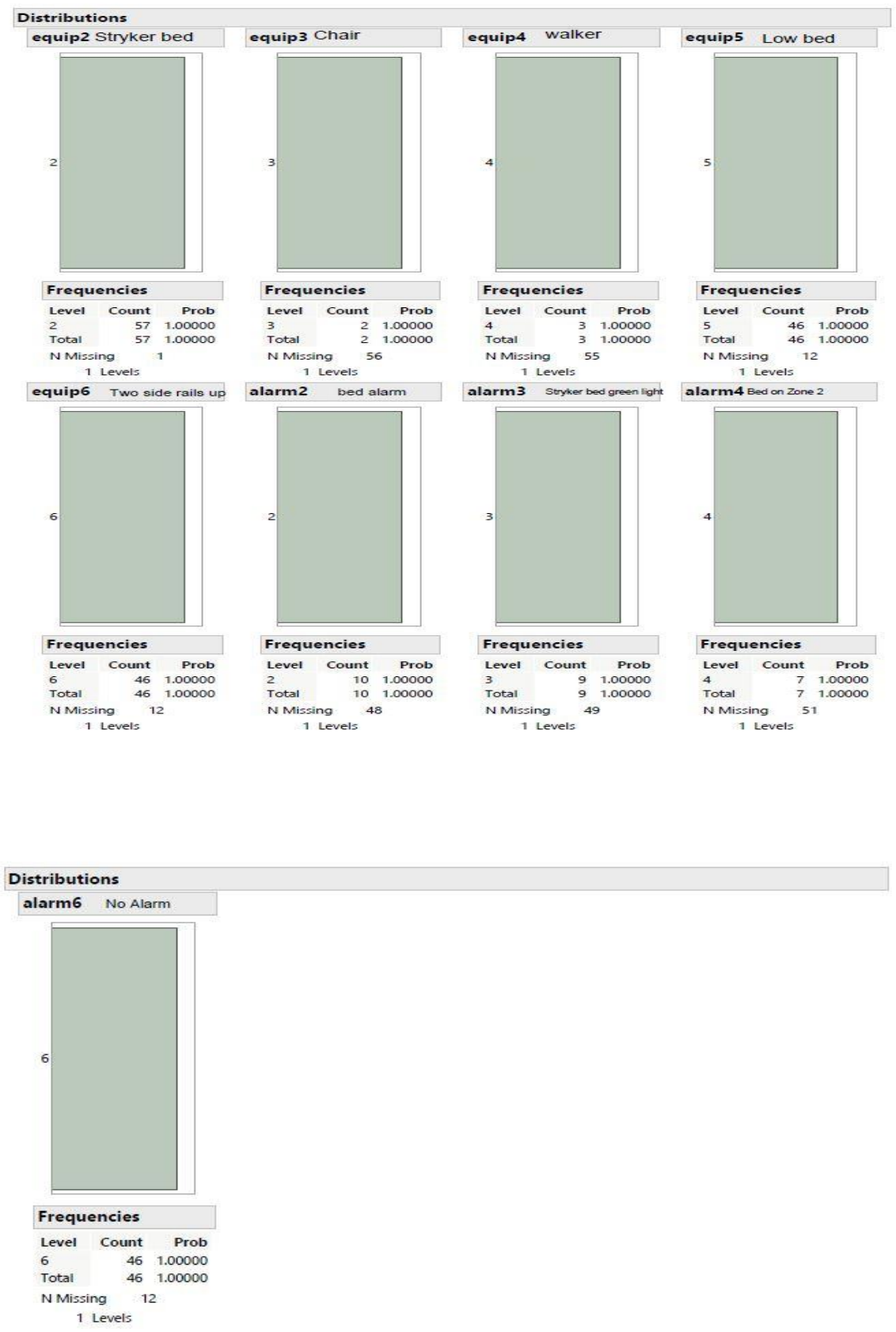


\section{Appendix R}

Audit Tool Results (Observation and Documentation)
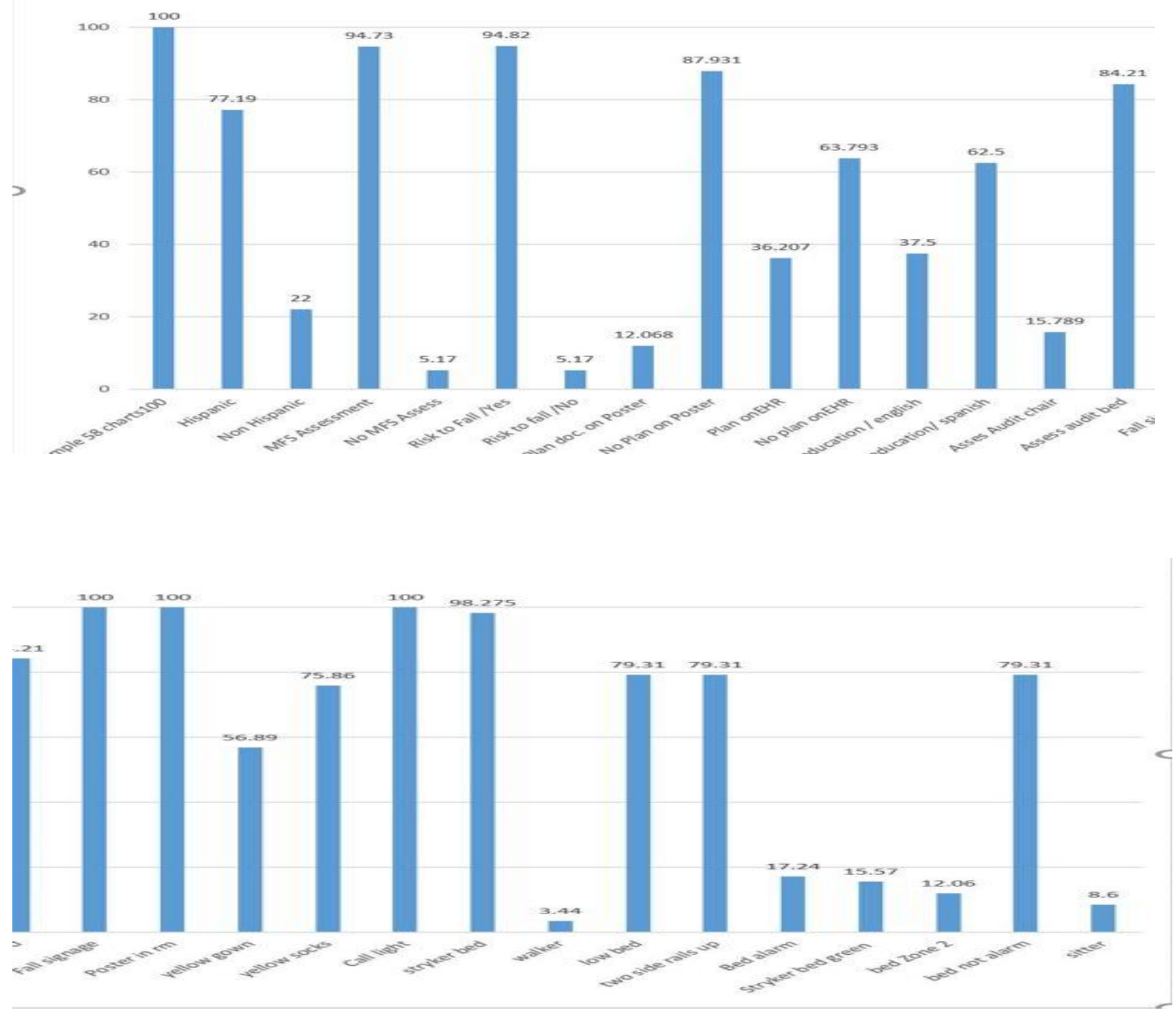


\section{Appendix S}

Pre and Post Intervention Fall Rate

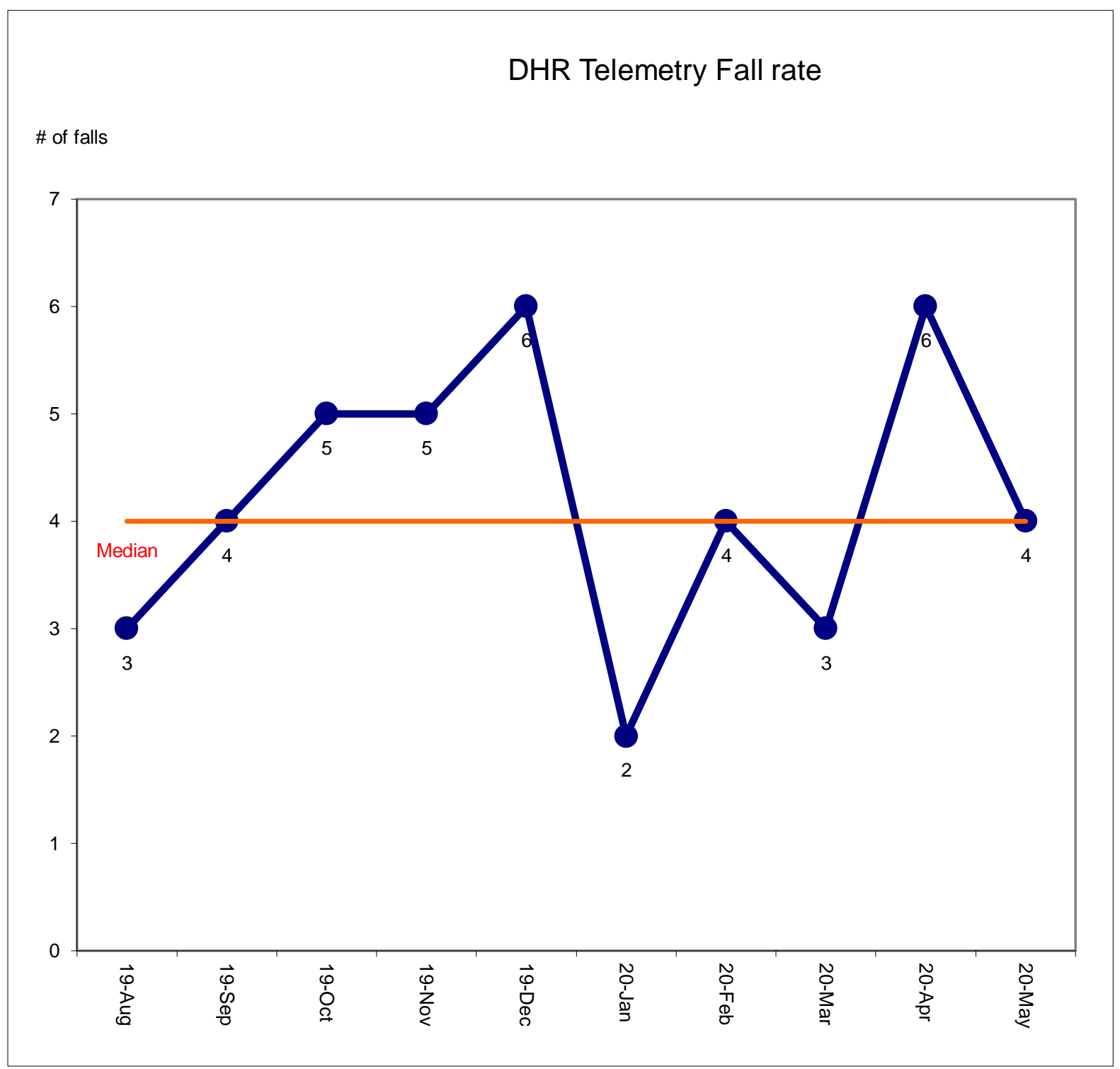




\section{Appendix T}

Risk Assessment and Tailored Intervention on the Poster

Risk assess and tailored intervention on poster

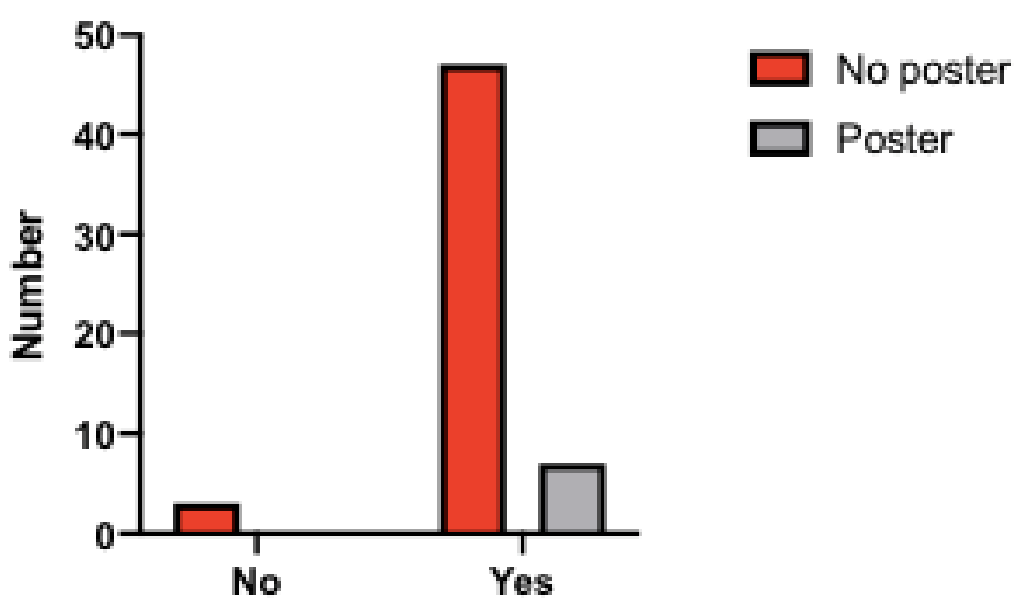

\begin{tabular}{|l|l|l|}
\hline Table Analyzed & Risk assess and poster & \\
\cline { 2 - 2 } & & \\
\hline P value and statistical significance & & \\
\hline Test & Fisher's exact test & \\
\hline P value & $>0.9999$ & \\
\hline P value summary & ns & \\
\hline One- or two-sided & Two-sided & \\
\hline Statistically significant $(P<0.05) ?$ & No & \\
\hline & & $95 \% \mathrm{Cl}$ \\
\hline Effect size & Value & 0.1152 to Infin \\
\hline Odds ratio & Infinity & 0.000 to $8.67 €$ \\
\hline Reciprocal of odds ratio & 0.000 & \\
\hline
\end{tabular}




\section{Appendix U}

Risk Assessment and Documentation of Tailored Intervention on the EHR

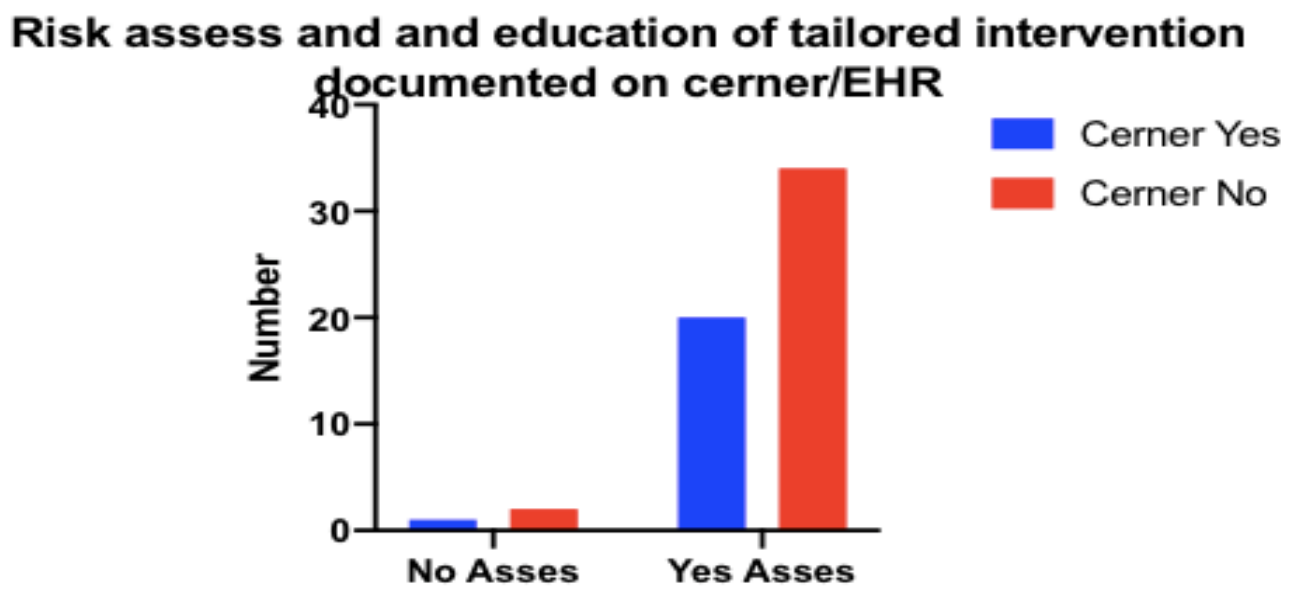

P value and statistical significance
Test
P value
P value summary
One- or two-sided
Statistically significant $(P<0.05)$ ?
Effect size
Relative Risk
Reciprocal of relative risk
Odds ratio
Reciprocal of odds ratio
Methods used to compute Cls
Relative Risk
Odds ratio
Data analyzed
No Asses
Yes Asses
Total
Norcentage of row total
Posses

Fisher's exact test $>0.9999$

ns

Two-sided

No

Value

0.9000

1.111

0.8500

1.176

Koopman asymptotic scc

Baptista-pike

Cerner Yes

1

20

21

Cerner Yes

$33.33 \%$

$37.04 \%$

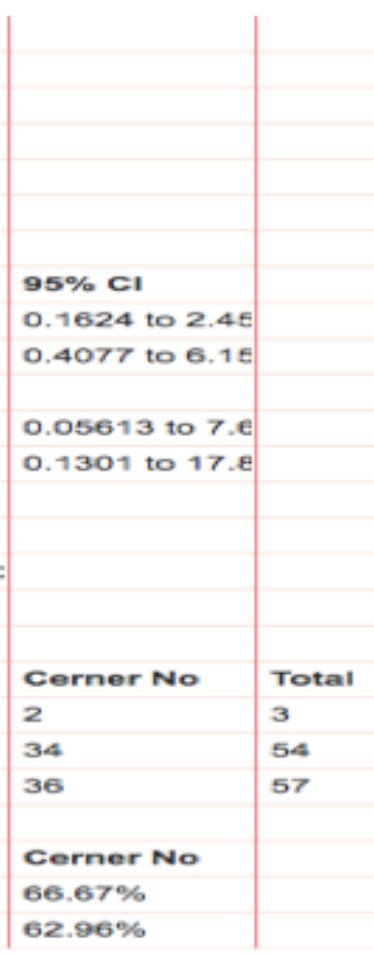




\section{Appendix V}

Morse Fall Assessment and use of Special Equipment

\section{Risk assessment and use of special equipment}

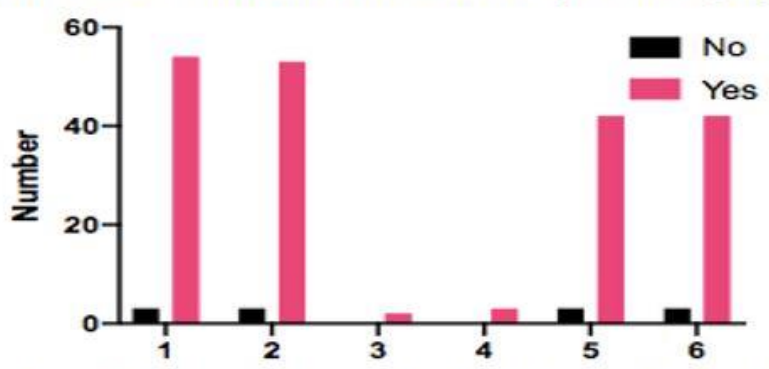

legend: 1-call light with in reach; 2-stryker bed; 3-chair; 4-walker ; 5 -low bed; 6 - two side rails up

\begin{tabular}{|l|l|}
\hline Table Analyzed & Risk assess and equip \\
\hline $\begin{array}{l}\text { P value and statistical significance } \\
\text { Test }\end{array}$ & \\
\hline Chi-square, df & Chi-square \\
\hline$P$ value & $0.4838,5$ \\
\hline$P$ value summary & 0.9927 \\
\hline One- or two-sided & ns \\
\hline Statistically significant $(P<0.05) ?$ & NA \\
\hline
\end{tabular}




\section{Appendix W}

Comparison Between Monthly Fall Rate Vs. Assessment

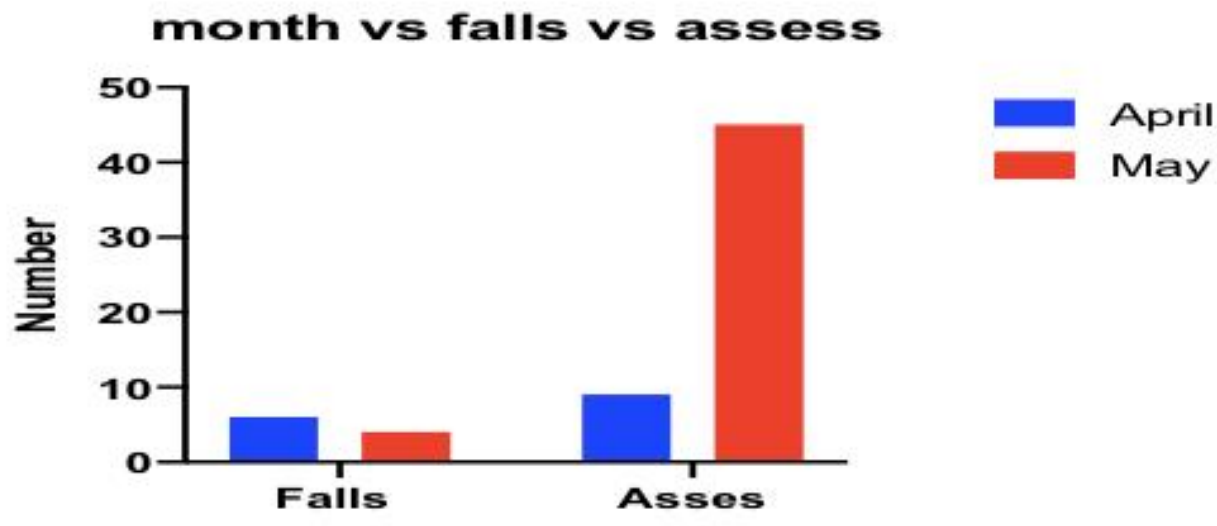

Test
P value
P value summary
One- or two-sided
Statistically significant $(P<0.0 s)$ ?
Erfect size
Relative Risk
Reciprocal of relative risk
Odds ratio
Reciprocal of odds ratio
Methods used to eompute Cle
Retative Risk
Odds ratio
Data analyzed
Falls
Asses
Total
Percentage of row total
Falls
Asses

\begin{tabular}{l} 
Fisher's exact test \\
0.0078 \\
Two-sided \\
Yos \\
Value \\
3.600 \\
0.2778 \\
7.500 \\
0.1333 \\
Koopman asymptotio soo \\
Baptista-pike \\
April \\
6 \\
9 \\
15 \\
April \\
$60.00 \%$ \\
$16.67 \%$ \\
\hline
\end{tabular}

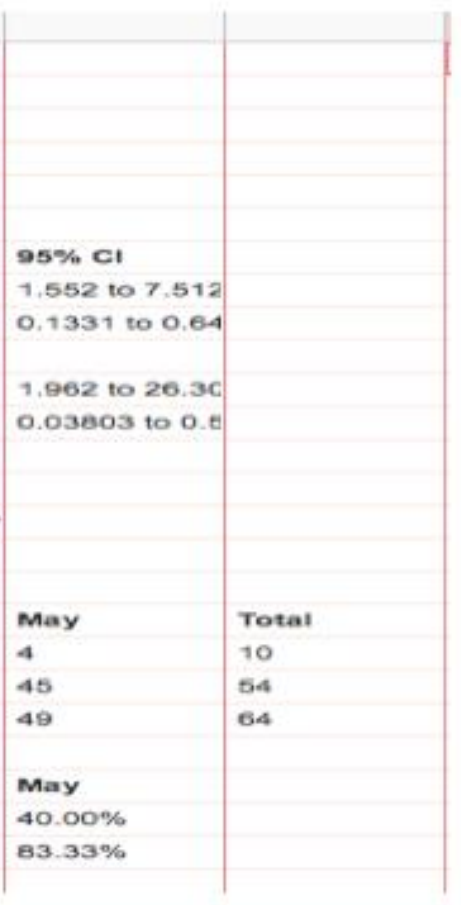

